\title{
A Dual Role of Amino Acids from Sesbania rostrata Seed Exudates in the Chemotaxis Response of Azorhizobium caulinodans ORS571
}

\author{
Xiaolin Liu, ${ }^{1,2}$ Zhihong Xie, ${ }^{1,+}$ Yixuan Wang, ${ }^{1,2}$ Yu Sun, ${ }^{1,2}$ Xiaoxiao Dang, ${ }^{1,2}$ and Haishuan Sun ${ }^{3}$ \\ ${ }^{1}$ Key Laboratory of Coastal Biology and Bioresource Utilization, Yantai Institute of Coastal Zone Research, Chinese Academy of \\ Sciences, Yantai, People's Republic of China \\ ${ }^{2}$ University of Chinese Academy of Sciences, Beijing, People's Republic of China \\ ${ }^{3}$ Shandong Huibang Bohai Agriculture Development Limited Company, Dongying, People's Republic of China
}

Accepted 25 March 2019.

\begin{abstract}
Azorhizobium caulinodans ORS571 can induce nodule formation on the roots and the stems of its host legume, Sesbania rostrata. Plant exudates are essential in the dialogue between microbes and their host plant and, in particular, amino acids can play an important role in the chemotactic response of bacteria. Histidine, arginine, and aspartate, which are the three most abundant amino acids present in $S$. rostrata seed exudates, behave as chemoattractants toward $A$. caulinodans. A position-specific-iterated BLAST analysis of the methyl-accepting chemotaxis proteins (MCPs) (chemoreceptors) in the genome of A. caulinodans was performed. Among the 43 MCP homologs, two MCPs harboring a dCache domain were selected as possible cognate amino acid MCPs. After analysis of relative gene expression levels and construction of a gene-deleted mutant strain, one of them, AZC_0821 designed as TlpH, was confirmed to be responsible for the chemotactic response to the three amino acids. In addition, it was found that these three amino acids can also influence chemotaxis of $A$. caulinodans independently of the chemosensory receptors, by being involved in the increase of the expression level of several che and fla genes involved in the chemotaxis pathway and flagella synthesis. Thus, the contribution of amino acids present in seed exudates is directly related to the role as chemoattractants and indirectly related to the role in the regulation of expression of key genes involved in chemotaxis and motility. This "dual role" is likely to influence the formation of biofilms by $A$. caulinodans and the host root colonization properties of this bacterium.
\end{abstract}

Keywords: genetics and gene regulation, molecular signaling, Rhizobium-legume symbiosis

${ }^{\dagger}$ Corresponding author: Z. Xie; zhxie@yic.ac.cn

Funding: This work is financed by NSFC-Shandong Joint Fund Key Projects (U1806206), the National Natural Science Foundation of China (31570063 and 31870020), Shandong Key Research and Development Program (2017GSF17129), Shandong Key Scientific and Technological Innovation Program (2017CXGC0303), and Agricultural Scientific and Technological Innovation Project of Shandong Academy of Agricultural Sciences (+CXGC2016B10).

*The $\boldsymbol{e}$-Xtra logo stands for "electronic extra" and indicates that one supplementary table and four supplementary figures are published online.

The author(s) declare no conflict of interest.

(c) 2019 The American Phytopathological Society
The establishment of specific, mutually beneficial relationships between microbes and plants depends on the exchange of molecular signals (Lopez-Baena et al. 2016). Nitrogen-fixing bacteria can fix atmospheric nitrogen to ensure the nitrogen nutrition of plants. In turn, plants and seed exudates contain a large variety of organic substances (including organic acids, sugars, amino acids, and aromatic compounds) providing an excellent niche for the growth of bacteria in the soil and the rhizosphere and which may also play an important role in the interaction between microorganisms and plants (Hartmann et al. 2009; Zhalnina et al. 2018). Organic compounds in seed exudates were reported to be used as growth substrates (Kamilova et al. 2006), as specific signals involved in chemotactic responses or in alternative cellular functions (Cai et al. 2009; Coskun et al. 2017; Yuan et al. 2015), or as both energy sources and signals at the same time.

The composition of plant roots and seed exudates influences signal exchanges between plants and microorganisms (GreerPhillips et al. 2004; Y. Liu et al. 2017). The secreted components as well as their functions differ between plants. Amino acids secreted by plants play a role in providing nutrients and signals, as well as in mechanisms of resistance to stress and virulence. Some bacteria such as Escherichia coli and Bacillus subtilis move toward amino acids which can be consumed rapidly, while nonutilized amino acids could not attract them (Yang et al. 2015).

The symbiotic relationship between rhizobia and the host is achieved through multiple steps, including chemotaxis, adhesion, colonization, proliferation, and infection. The root environment is complex and bacteria need to respond quickly to external signal stimuli. Chemotaxis appears as the earliest fundamental event in most plant-microbe interactions (Brencic and Winans 2005). Amino acids can work as specific signals during the process. The response of bacteria to external signals is mainly dependent on their chemosensory system (Krell 2018; Wuichet and Zhulin 2010). Chemotaxis is the process by which bacteria move toward a higher concentration of attractive molecules or away from repellent molecules. The chemotactic response is stimulated by external nutrients and signals. In E. coli and many other bacterial species, the signal transduction pathway involves the two-component system CheA and CheY, whose phosphorylation state is directly correlated to the functioning of the flagellar motor (Wadhams and Armitage 2004). Soil bacteria generally have numerous methyl-accepting chemotaxis proteins (MCPs) (Allard-Massicotte et al. 2016). In particular, nitrogen-fixing bacteria generally harbor nine to 90 
genes encoding methylation receptors (Salah Ud-Din and Roujeinikova 2017).

Azorhizobium caulinodans ORS571 is a rhizobium with a complex life style, which can fix nitrogen in the free-living state or induce nodule formation on the stem and the roots of its legume host, Sesbania rostrata (Dreyfus et al. 1983; Elmerich et al. 1982). There are two routes of invasion for A. caulinodans to form root nodules (Goormachtig et al. 2004). Root hair invasion and the intercellular invasion at lateral root bases are the two best-known ways. Under flooded conditions, the root hair invasion can be inhibited completely (Capoen et al. 2010). It was also reported that the bacteria can associate with nonlegumes to fix nitrogen (Qiu et al. 2017; Webster et al. 1998). In a former work, analysis of the A. caulinodans ORS571 genome revealed the presence of $43 \mathrm{MCP}$ structural gene homologs distributed along the genome (Jiang et al. 2016b). Two of them, IcpB and TlpA1, have been studied in detail. IcpB, encoded by $i c p B$, is a soluble MCP, which can sense oxygen through a hemebound cofactor (Jiang et al. 2016a), while TlpA1 is a transmembrane MCP protein, encoded by the $\operatorname{tlpAl}$ gene located upstream of che cluster (W. Liu et al. 2018). TlpA1 can respond to multiple chemoeffectors, including succinate, citrate, proline, tartrate, malate, and glycerol (W. Liu et al. 2017). Both IcpB and TlpA1 participate in the modulation of nodulation (Jiang et al. 2016a; W. Liu et al. 2017). As mentioned above, the distribution of genes encoding MCP proteins is widespread among bacteria, while the high divergence of the periplasmic ligand-binding region (LBR) makes it difficult to annotate the functions of MCP (Lacal et al. 2010; Wuichet et al. 2007).

In this work, the composition and the relative concentration of amino acids in the $S$. rostrata seed exudates was determined and the effect of the three main amino acids-histidine, arginine, and aspartate- on growth of A. caulinodans ORS571 was studied. In addition, we assessed the characteristics of the chemotactic response to the three most abundant amino acids, and identified their cognate chemoreceptor, TlpH. Interestingly, these amino acids were also found to play a role in the chemotactic response to succinate, independently of $\mathrm{TlpH}$ and TlpA1, by regulating the expression level of che and fla genes encoding chemotaxis-pathway and flagella synthesis-related proteins. It was further established that these three amino acids negatively regulate the colonization of $A$. caulinodans through an unknown mechanism independent of $\mathrm{TlpH}$.

\section{RESULTS}

\section{Amino acid analysis of seed exudates and their effect on A. caulinodans ORS571 growth.}

The composition and concentration of organic compounds in samples of seed exudates of $S$. rostrata was determined to identify the most abundant amino acids produced (Fig. 1A) (see Materials and Methods). The amino acid content of the seed secretions represented up to $5.26 \%$ of the total organic compounds (Fig. 1B). Among them, 17 amino acids were identified on the basis of retention times compared with standard samples. The most abundant amino acids were histidine, arginine, and aspartate, with histidine representing more than $50 \%$ of all the amino acids present in exudates. Thus, we focused on histidine, arginine, and aspartate to establish whether these amino acids can be used as energy sources to support growth of A. caulinodans ORS571.

First, the ability of amino acids or seed exudate to serve as the carbon source was assessed in minimal medium containing $\mathrm{NH}_{4} \mathrm{Cl}$ as the nitrogen source. L3 medium with succinate as the carbon source was used as a control. Seed exudates can support growth to some extent and aspartate showed a very small

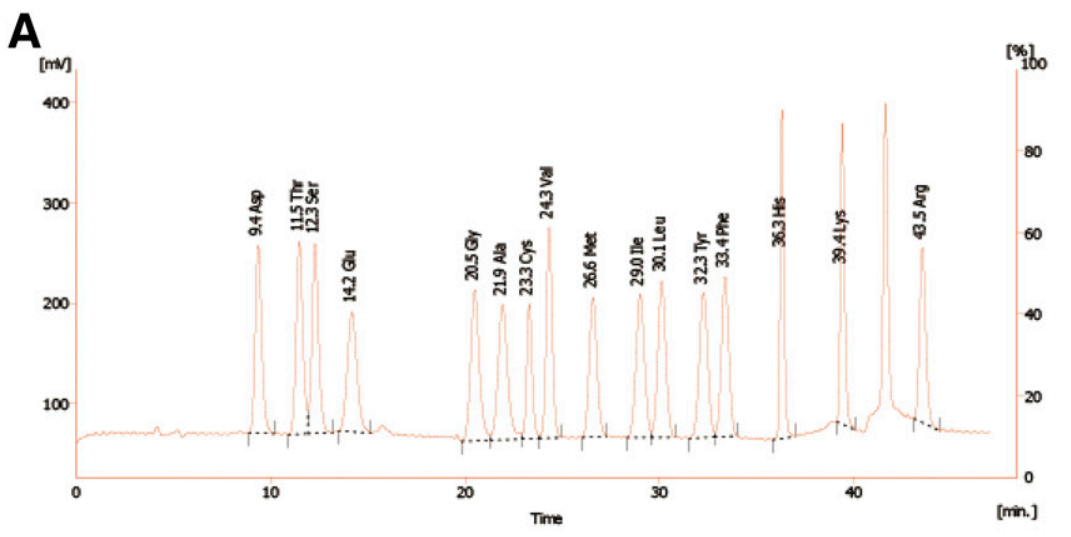

B
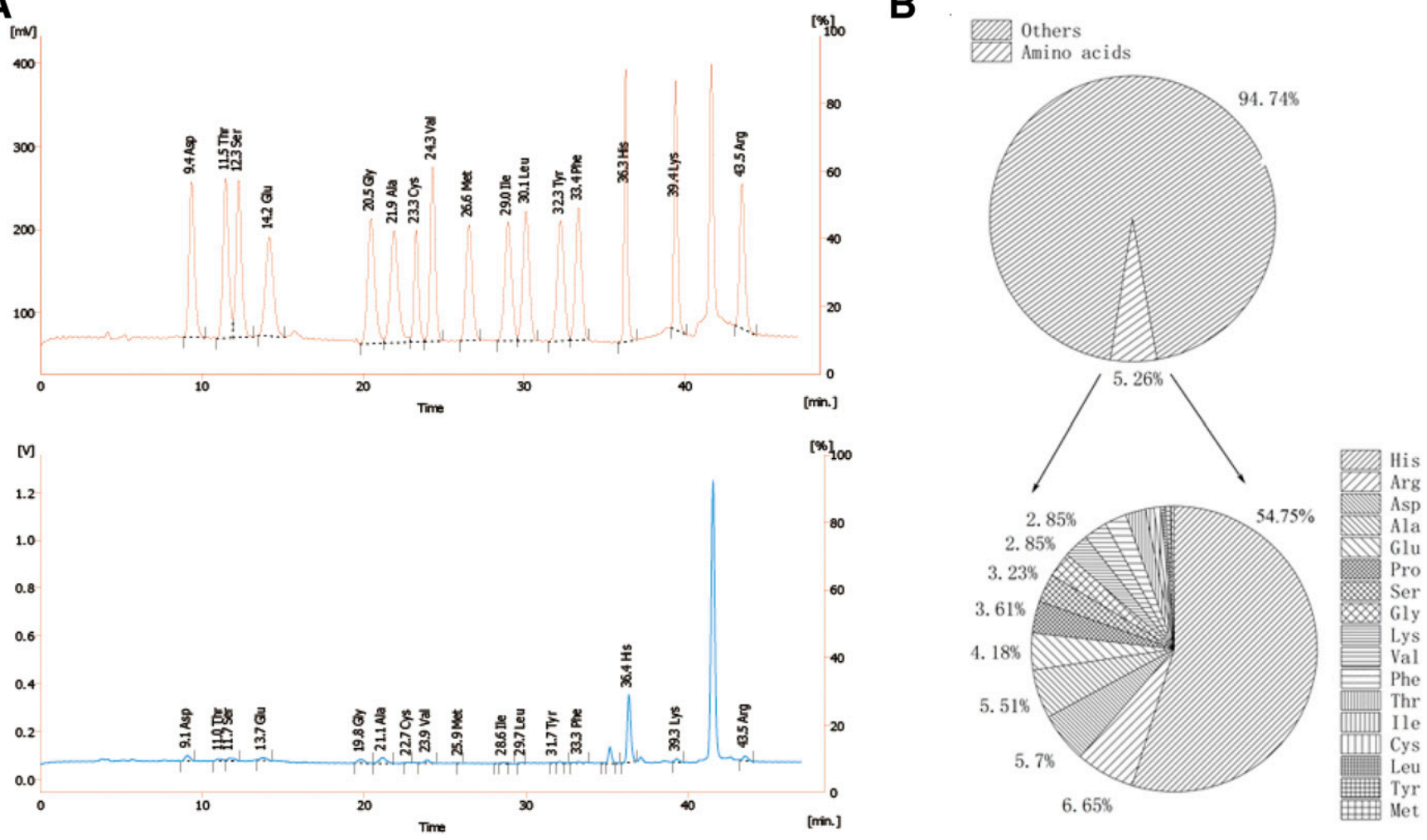

Fig. 1. Composition and concentration of amino acids in Sesbania rostrata seed exudates. A, Chromatogram showing elution retention time of amino acids standard compounds (top) and seed exudates (bottom). B, Diagram showing the percent content of amino acids (top) and percentage of each amino acid in seed exudates (bottom). 
increase, whereas histidine and arginine cannot support growth of ORS571 under this condition (Fig. 2A; Supplementary Fig. $\mathrm{S} 1)$. Then, the roles of amino acids used as nitrogen source were assessed in L3 minimal medium containing succinate as carbon source but without $\mathrm{NH}_{4} \mathrm{Cl}$. In the medium plus aspartate, cells can grow up to an optical density at $600 \mathrm{~nm}\left(\mathrm{OD}_{600}\right)$ of 0.8 (Fig. 2B), indicating that aspartate can be used as a nitrogen source, whereas arginine and histidine cannot promote growth. Next, we analyzed the growth of ORS571 in medium without any carbon and nitrogen sources, except for histidine, arginine, or aspartate. The absence of growth showed that these amino acids cannot be used as sole energy sources (Fig. 2C). Weak growth (Fig. 2C) in the negative control might reflect the fact that nicotinic acid, which is a growth factor for the strain, can be used as an energy source for growth (Elmerich et al. 1983). Finally, in the presence of succinate and $\mathrm{NH}_{4} \mathrm{Cl}$, these three amino acids cannot affect the growth of ORS571 significantly (Fig. 2D).

Analysis of the A. caulinodans ORS571 genome did not reveal the presence of genes involved in arginine or histidine
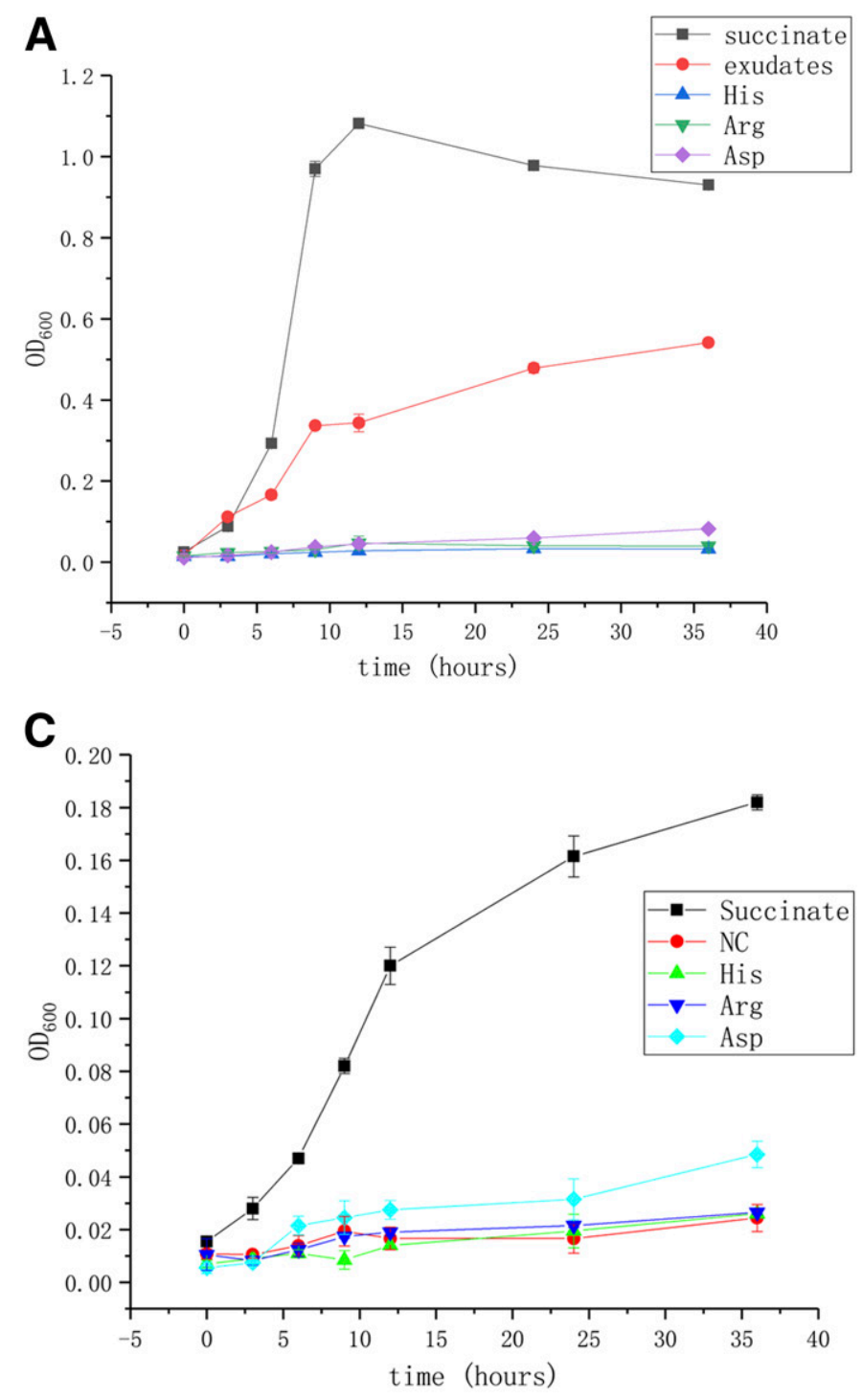

catabolism, in agreement with the fact that these amino acids cannot be used as sole carbon source or nitrogen source. Formation of aggregates in the culture medium was observed when aspartate, histidine, or arginine was used as sole source of nitrogen (Supplementary Fig. S2). Aggregate formation enhances the ability of bacteria to endure ambient stresses such as high aeration and nitrogen limitation (Bible et al. 2015). When $1 \mathrm{mM} \mathrm{NH} \mathrm{N}_{4} \mathrm{Cl}$ was added to the medium, no aggregates were formed, consistent with the results that succinate and $\mathrm{NH}_{4} \mathrm{Cl}$ were the preferred carbon and nitrogen sources.

\section{Characterization of chemotaxis of ORS571}

\section{to exudates and some amino acids.}

To investigate the role of seed exudates and amino acids in chemotaxis of ORS571, we conducted traditional quantitative capillary chemotaxis assays under various amino acids gradient. Capillaries containing phosphate-buffered saline (PBS) buffer were used as controls. When capillaries were filled with seed exudates, more than 1,500 cells were attracted by them
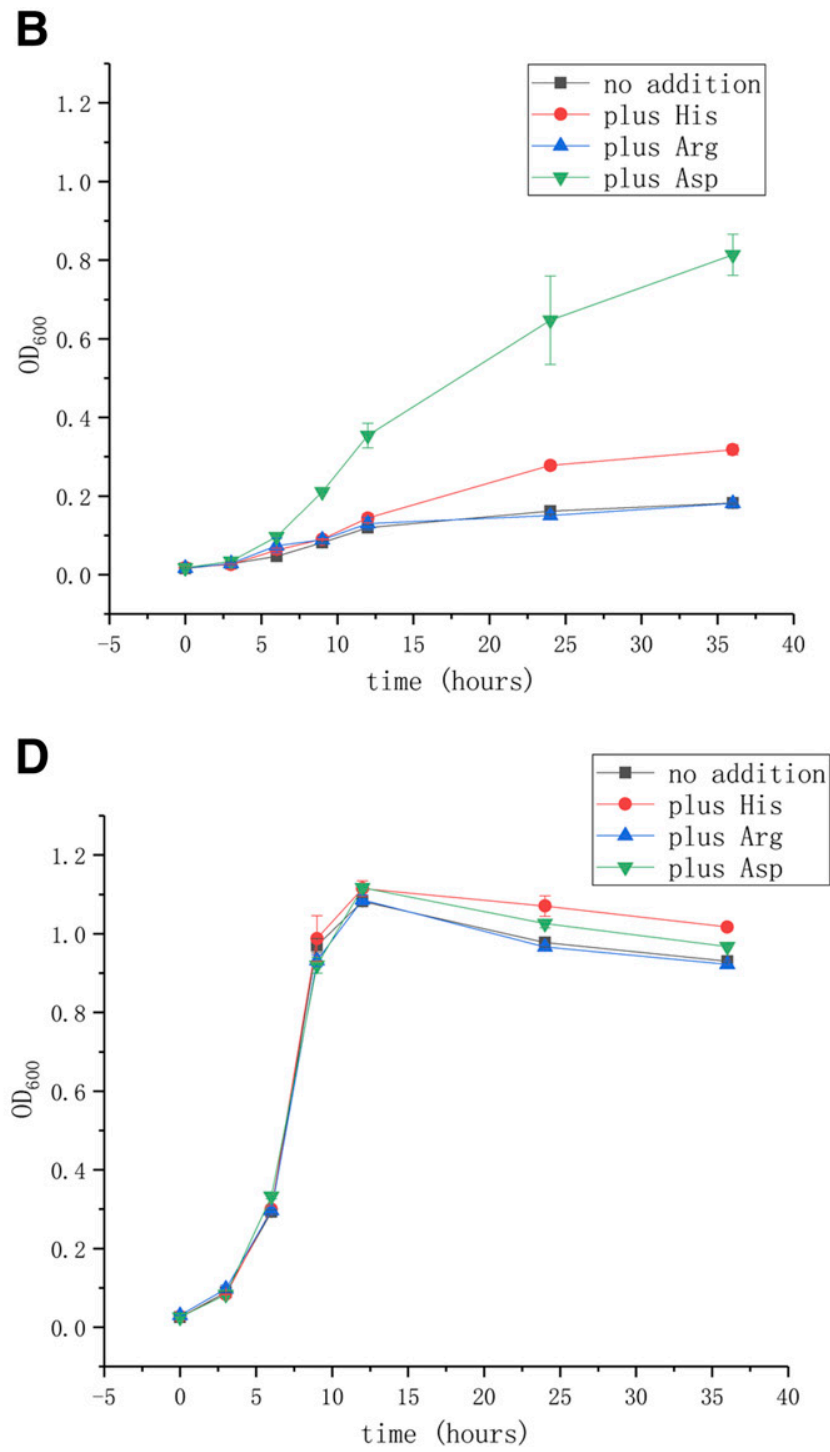

Fig. 2. Utilization of amino acids for the growth of Azorhizobium caulinodans ORS571 under various conditions. A, Comparative growth in L3 mineral base medium containing either succinate (10 mM), seed exudates, $10 \mathrm{mM}$ histidine (His), $10 \mathrm{mM}$ arginine (Arg), or $10 \mathrm{mM}$ aspartate (Asp) as sole carbon source and supplemented with $1 \mathrm{mM} \mathrm{NH}_{4} \mathrm{Cl}$ as nitrogen source. $\mathbf{B}$, Without $\mathrm{NH}_{4} \mathrm{Cl}$, each amino acid was used as sole nitrogen source in $\mathrm{L} 3$ minimal medium containing $10 \mathrm{mM}$ succinate as carbon source. $\mathbf{C}$, Without $\mathrm{NH}_{4} \mathrm{Cl}$ and succinate, each amino acid was used as carbon and nitrogen source at the same time. Negative control (NC) means that no other substances were added in the absence of $\mathrm{NH}_{4} \mathrm{Cl}$ and succinate. $\mathbf{D}$, In the presence of $\mathrm{NH}_{4} \mathrm{Cl}$ and succinate, the $\mathrm{L} 3$ medium was supplemented with additional histidine, arginine, or aspartate separately. 
(Fig. 3A). Dose dependence of chemotaxis to amino acids from $10 \mu \mathrm{M}$ to $10 \mathrm{mM}$ was assayed (Fig. 3B). For histidine, the chemotactic response increased with the amino acid concentration, and the strongest chemotaxis response was at $10 \mathrm{mM}$, although $1 \mathrm{mM}$ arginine or aspartate can trigger the strongest chemotaxis response of ORS571.

The soft-agar plate assay is commonly used to determine chemotactic characteristics of attractants (Yao and Allen 2006). In this system, bacteria can utilize the growth substrate and move gradually along the gradients. However, because these amino acids cannot be utilized as sole nitrogen or carbon source, the traditional soft-agar plate method cannot be used. Therefore, we used modified traditional soft-agar assays with artificial gradients of amino acids (Fig. 3C).

First, we confirmed the effectiveness of this method (Supplementary Fig. S3). We constructed an artifact spatial gradient of succinate on a soft-agar plate. Then, ORS571 was dropped on the center of the plate, and nonchemotactic mutant cheZ was used as a negative control. A big circle and a small sharp ellipse (inside the circle) were formed on the plate after culturing for $24 \mathrm{~h}$. The formation of a sharp ellipse is due to most cells moving toward sites containing a high concentration of succinate. Although the succinate in the horizontal direction can form a horizontal gradient due to the gradual metabolism of succinate, the bacteria tend to longitudinally move along the direction of high succinate. These results showed that this method can be used to measure the chemotactic response of potential attractants.

Using artificial gradients of amino acids on the soft-agar assay, two chemotaxis rings can be seen: an inner sharp circle ring resulted from succinate chemotaxis, while the outer sharp ellipse was formed along the amino acid gradient, with cells moving more toward regions of high amino acid concentration (Fig. 3D).

\section{Alignment and bioinformatics analysis of mcps in ORS571 genome.}

Forty-three MCP homologs have been annotated in the A. caulinodans ORS571 genome (Jiang et al. 2016b). To identify the MCP responsible for the chemotactic response to these
A

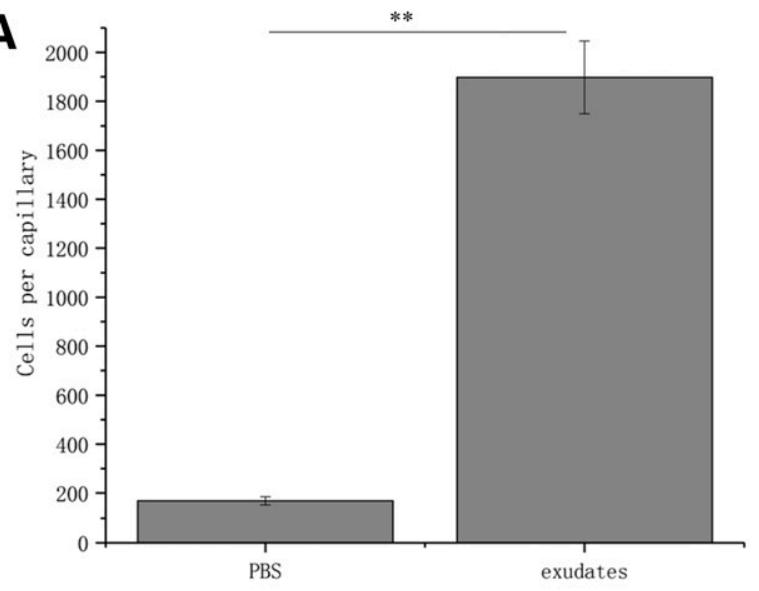

B

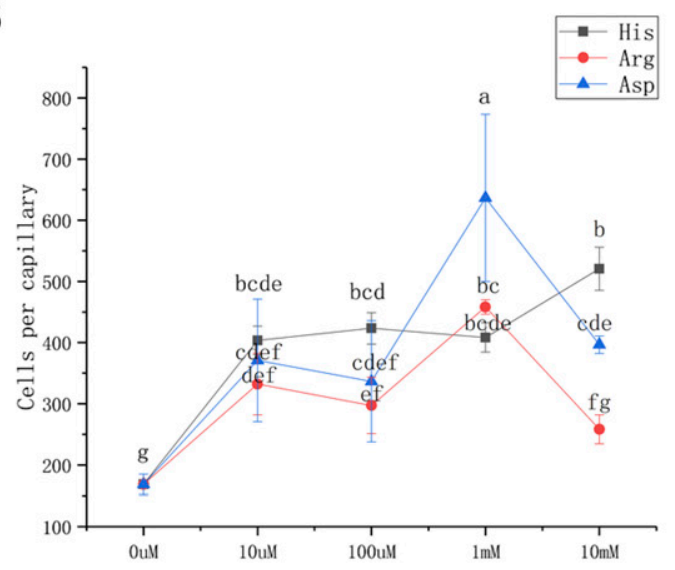

C

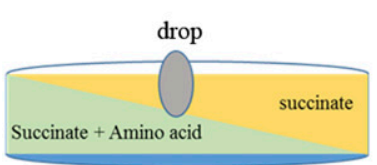

D

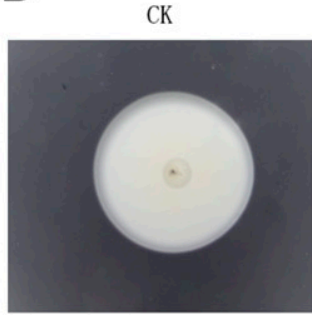

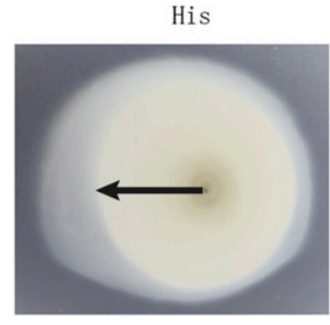

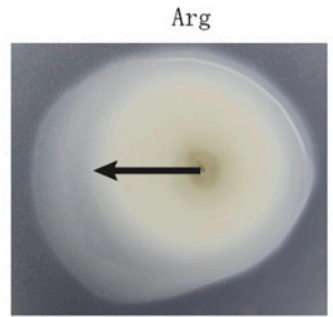

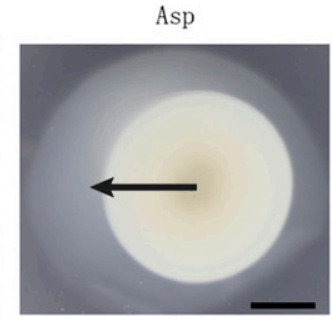

Fig. 3. Characterization of chemotaxis of ORS571 to seed exudates and to some amino acids. The capillary assay was used to determine the chemotaxis responses of $\mathbf{A}$, seed exudates and $\mathbf{B}$, amino acids at different concentrations. His $=$ histidine, $\mathrm{Arg}=\operatorname{arginine}$, and Asp $=$ aspartate. $\mathbf{C}, \mathrm{A}$ modified soft-agar plate was used to determine $\mathbf{D}$, the chemotactic response toward amino acids. $\mathrm{L} 3$ soft-agar medium with $10 \mathrm{mM}$ succinate as sole carbon source and $1 \mathrm{mM} \mathrm{NH}_{4} \mathrm{Cl}$ as nitrogen source was used as a control (CK). Arrows indicate the direction of movement, and the scale bars represent $1 \mathrm{~cm}$. Values are means \pm standard deviation from at least three independent experiments. Asterisks (**) indicate a significant difference from the phosphate-buffered saline control, as analyzed by SPSS using Tukey's test $(P<0.01)$.

Table 1. Percentages of identity/similarity between AZC_0254 and AZC_0821 and the five Pseudomonas aeruginosa proteins identified as best hit from the PSI-BLAST analysis ${ }^{\mathrm{a}}$

\begin{tabular}{lclc}
\hline AZC_0254 & Identity/similarity (\%) & AZC_0821 & Identity/similarity (\%) \\
\hline McpU (polyamines) & $26.3 / 42.9$ & McpA (amino acids) \\
PctC (amino acids) & $22.5 / 39.9$ & PctB (amino acids) \\
PctB (amino acids) & $24.4 / 40.5$ & PctA (amino acids) \\
McpA (amino acids) & $25.1 / 39.4$ & PctC (amino acids) \\
PctA (amino acids) & $23.9 / 39.8$ & McpG ( $\gamma$-aminobutyric acid) \\
\hline
\end{tabular}

\footnotetext{
a The specific ligand for each protein is indicated between parentheses.
} 
amino acids, we performed position-specific-iterated (PSI)BLAST of each ORS571 MCP amino acid sequence to identify possible amino acid cognate $\mathrm{MCP}$ proteins.

Two hypothetical MCPs (AZC_0254 and AZC_0821) of A. caulinodans were found to share similarity with five MCP proteins from Pseudomonas aeruginosa (McpU, McpA, PctA PctB, and PctC) (Table 1; Supplementary Table S1). The five identified proteins (Table 1) possess a dCache domain reported for sensing amino acids (Upadhyay et al. 2016) within the LBR (Fig. 4A). Indeed, all of these proteins, except McpG and

A

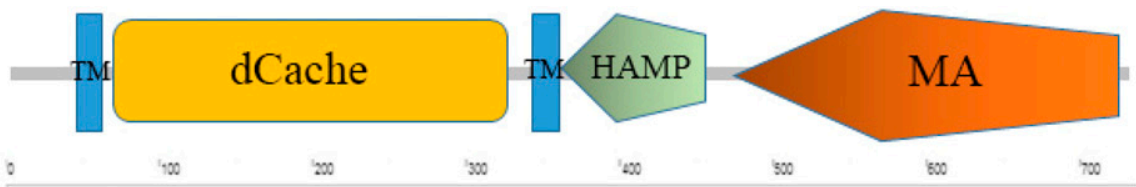

B

0254

0821

McpA

PctB

PctA

PctC

McpG

$\mathrm{McpU}$

cons

0254

0821

McpA

PctB

PctA

PctC

McpG

$\mathrm{McpU}$

cons

0254

0821

McpA

PctB

PctA

PctC

McpG

$\mathrm{McpU}$

cons

0254

O821

McpA

PctB

PctA

PctC

McpG

$\mathrm{MCpU}$

cons

0254

0821

McpA

PctB

PctA

PctC

McpG

$\mathrm{McpU}$

cons

STSRDSLQRL - - - A ASVQAAAIRTE IDSAFDAARVMARALEVVAENDGVGSARDQRRGQLNALLLSVLKNNTR - SAVQLDAERRGQAL AKDSARTIAAQVEEAALTARAAATAIEGFIGEKG - - - GD - - RDRLGFVLSGLVAENPA - NTIRQNIEASVQQSGALTASSVQNWMSGRILVL $\ldots \ldots$ ENLA $\ldots$. $\ldots$ QDIGQQGA $\cdots \cdots \cdots$ ASIREDLEDYLHEMGE ITASNVQNWLSGRILLI $\ldots \ldots . . . \cdots$

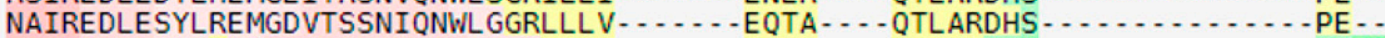

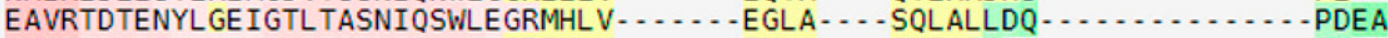
NAIREDLENYLAEMGASTSTNIRNLFEGRIKLV $\ldots \ldots$ ENLA $\ldots . .$. QNIAQD $\ldots . . . . . . . . .$. AMLEDSARQRLQAHAETQALRIQRYFMDAYQYGNGFARLVQVLKDRG - - - GSDL - RAELTRQARASLAGNPD - -

FNGTYSAW/MPDALDGADPLNIGRKDIGSDATGRALPYWTRDAAGNIALOPL $-\mathrm{V} \ldots \ldots$. . . LAGMTLAFESGKLDGQDKDFAGHAL - ADSTGRFSARFYRDAGGSVAREAVNV $\ldots \ldots \ldots$ SQDG $\ldots \ldots \ldots$

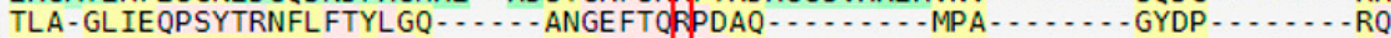

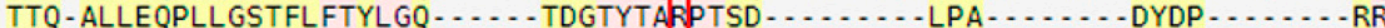

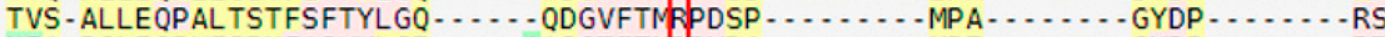

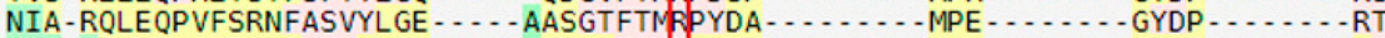
NAE - TLMGQNALISSFLTVYLGK $\ldots . .$. VDGGFSVBPDAK $\ldots \ldots \ldots$ MPD $\ldots \ldots \ldots$ GYDP $\ldots . . .$. RT VIGLYLVFQPNALDQQDSHYLGQDAMGSNESGRFSLYWISQPSPGTLELEAMPETMLGDTSIGSNG - . . . . . AAK

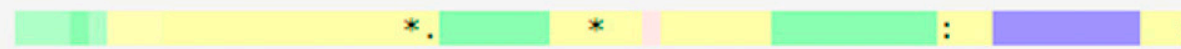

GGWFIGPQTTGKESILAPLPYVVQGKSVYLATMSVPI - - MVGGRFAGVAGACFDLSFVQSLAEKVDRSIYKGQGT QRWYPSAVQQGRAVATPAMAAVFGGRPVKVVTVAVPV - - RRAGTPIGVVAVDLPLERIAR - - TVADLKPFGTGV RPWVYGAAANAGQTVL TAP M QGAVGGL - . - MVTIATPVKSKRNGEL IGVVGGDVTLDTLVE - - - IINSVDFGGIGH RPWWYNAATSAGQTTL TEP YMEPAIHE - - LVLTIASPA - RQGGQP FGVVGGDLSLQTVVK - - - I INSLDFGGMGY RPWYYKDAVAAGGL TL TEP YVDAATQE - - LIITAATPV - - KAAGNTLGVVGGDLSLKTLVQ - - - IINSLDFSGMGY RAWYKDAL AADRL IVTEP F DAGTGE - - QILAMSLPV - RHAGQLLGVAAGDMKLETLTA - - ILNSLKFDGAGY RPW WYKD GMNASGATL TEP YIDMTTNK - - MVIGILSK - . . . - VSSSVGVVGGDLALDGLVQ - . - I INSLNFGGMGY NRW.TCPQDTARTCMLEP UDEVNGRQVLMTSIALPL - - LEHGKVVGVVGLDIGLANLQQLSVNGRRDLFDGQGQ

$$
*
$$
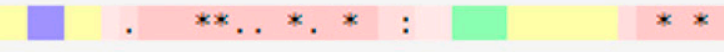

VSIVTNAGLVVASSADPRSIGGPYKAIEPQAEQDMDTLRKGEEAVKLD - . . TAK - . . . . - DAIK - VFAPVA AAVVGSDGNWLAGAE - AERVGGAVTDPALTA - - L VKDAAGGKPVQRIIYTDEGKTFCGVCTTL IR - L - AFTLTG

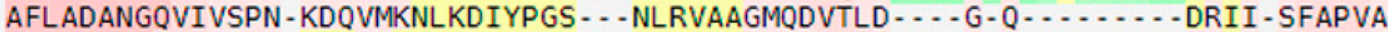

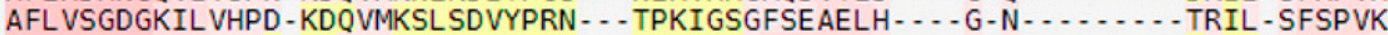
AFLVSGDGKIL VHPD - KEQVMKTLSEVYPQN - . TPKIATGFSEAELH . . . - G - . . . . . . . TRIL - AFTPIK AFLVSDAGKILLHPD - SGLVLKTLAEAYPKG $\ldots$ APNIVPGVHEVELD $\ldots$. . AFL VNDQGKIL VHPD - KDL VMKSLSDLFPQH - - TPKLTGELTEVQSD - . - G - . . . . . . TRLL - TFSPIT

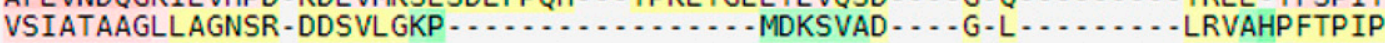
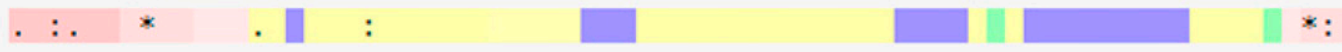

LGRTGGAWSVII - .... T - TYDSATFYAFASQVQIA

- GLPSAQWYIGL -....-S

- GLSGLDWYIGI . . . . . S

-GLPSVTWYLAL ..... - S

- GLPGVTWYVAL ...... V

-GLPSANWYIGL ..... - S

... DTAPWQVVL......

Fig. 4. Bioinformatics analysis and multiple alignment of methyl-accepting chemotaxis protein (MCP) amino acid sequences. A, Scheme of the protein domain organization of AZC_0254 and AZC_0821. B, Multiple alignment with template and partial target proteins (McpA, PctB, PctA, PctC, McpG, and McpU from Pseudomonas aeruginosa). Perfectly conserved sites are indicated with asterisks; a colon and a dot indicate conservative and less conservative substitutions, separately. Shading indicates the extent of conservation of each site. 
McpU, were reported to regulate the chemotactic response to proteinogenic amino acids (Kuroda et al. 1995; Taguchi et al. 1997). McpG plays a role on chemotaxis response to the nonproteinogenic amino acid $\gamma$-aminobutyric acid in Pseudomonas (Reyes-Darias et al. 2015), while McpU regulates chemotactic response to different polyamines (Corral-Lugo et al. 2016). AZC_0254 shares the highest similarity with $\mathrm{McpU}$, while AZC_0821 has the highest similarity with PctC (Table 1). The identity and similarity between AZC_0254 and AZC_0821 is 31.7 and $48.1 \%$, respectively, and both possess a dCache domain within their LBRs (Fig. 4A).

The three-dimensional structure of $P$. aeruginosa PctA has been resolved (Rico-Jiménez et al. 2013b), enabling the identification of critical amino acid residues in the active site involved in the chemoeffector amino acid binding (Rico-Jiménez et al. 2013a). Sequence alignments show that four critical residues (such as arginine, tryptophan, tyrosine, and aspartate) are conserved in AZC_0821, whereas only two (tryptophan and aspartate) are conserved in AZC_0254 (Fig. 4B).

\section{Relative expression of mcps in ORS571 and the chemotactic response}

of the $\Delta t$ tpH mutant strain to amino acids.

Expression of structural genes encoding MCP was reported to be induced by cognate chemoeffecors in $P$. putida KT2440. Indeed, mRNA levels between the most- and least-abundant chemoreceptors in the $P$. putida genome are significantly different, up to 174-fold (López-Farfán et al. 2017). Thus, realtime quantitative PCR (RT-qPCR) was performed to determine changes induced by amino acids in the expression of the $43 \mathrm{mcp}$ genes identified in A. caulinodans. However, we failed to obtain reproducible results (data not shown) and focused only on $a z c \_0821$ and $a z c \_0254$. Expression of $a z c \_0821$ was much higher than that of $a z c \_0254$ in the different media and growth phases (Fig. 5). Because a direct correlation was reported between the level of expression of $m c p$ genes and the importance of chemotactic response to the environmental stimuli (Kalinin et al. 2010), it is proposed that AZC_0821 might play a more important role as chemoreceptor for amino acids than AZC_0254.

To further explore the role of AZC_0821 on chemotaxis of amino acids, we engineered a mutant strain carrying a deletion of azc_0821 in the chromosome of A. caulinodans ORS571. Motility and growth of the $a z c \_0821$ mutant did not differ from that of the wild type (data not shown). Chemotactic

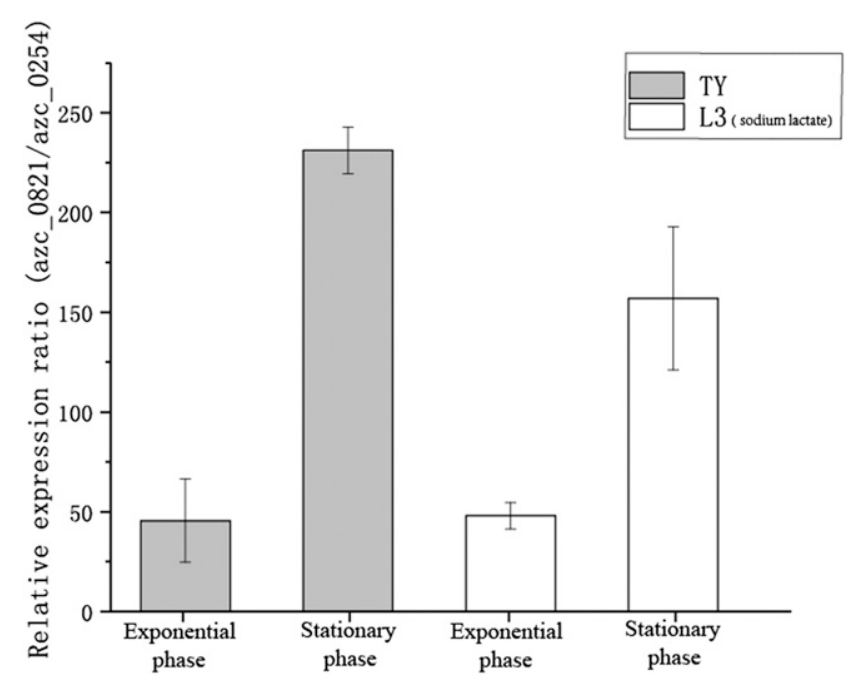

Fig. 5. Relative expression ratio of $a z c \_0821$ to $a z c \_0254$ under different conditions. Data are expressed as means \pm standard deviation of least three independent experiences. response was investigated by capillary assay using, as a negative control, the cheZ mutant $(\Delta c h e Z)$, whose chemotactic ability is abolished (X. Liu et al. 2018). In all, $10 \mathrm{mM}$ histidine, $1 \mathrm{mM}$ arginine, and $1 \mathrm{mM}$ aspartate were used as attractants separately. The azc_0821 mutant strain was null for chemotaxis to histidine $(10 \mathrm{mM})$ and arginine $(1 \mathrm{mM})$ and had a significant defect for chemotaxis to aspartate $(1 \mathrm{mM})$ (Fig. 6). The phenotype of $a z c \_0821$ mutant could be complemented with pBBR1MCS2-com, including intact $a z c \_0821$ ORF from its native promoter (Fig. 6). These results showed that AZC_0821 was responsible for chemosensing of amino acids, and it was renamed as $t l p H$ (transducer-like protein for histidine and some other amino acids) in ORS571.

\section{Amino acids from seed exudates can promote} the chemotactic response to succinate indirectly.

Chemotaxis of ORS571 on modified soft-agar plates with or without amino acids was analyzed with succinate as the carbon source. Interestingly, the chemotactic ring formed on plates in the presence of the amino acid gradients was larger than that with succinate only (Fig. 3D). This led us to further analyze the effect of amino acids on the chemotaxis response to succinate.

This analysis was performed by using traditional soft-agar plates, with succinate as sole carbon source and containing or not one of the three amino acids. In that system, there is no gradient of amino acids on the soft-agar plate; no amino acid gradients can be formed with time because these amino acids cannot be utilized for growth (Fig. 2). Thus, one can rule out that the increase in the chemotactic ring is linked to a chemotactic response toward amino acids. In the absence of amino acid, a big and sharp chemotactic ring is formed by the wildtype strain. While adding the single amino acid histidine $(10 \mathrm{mM})$, arginine $(1 \mathrm{mM})$, or aspartate $(1 \mathrm{mM})$, the chemotactic rings of succinate were significantly increased by approximately $30 \%$ (Fig. 7A and B). Interestingly, the behavior of the $\Delta t l p H$ mutant strain, which is deficient in its chemotactic response toward the three amino acids, was similar to that of the wild type (Fig. 7A and B), indicating that the effect of amino acids on the succinate chemotaxis was independent of TlpH. The chemotactic rings to succinate formed by the previously described MCP mutant $\triangle t l p A l$ are smaller than those of the

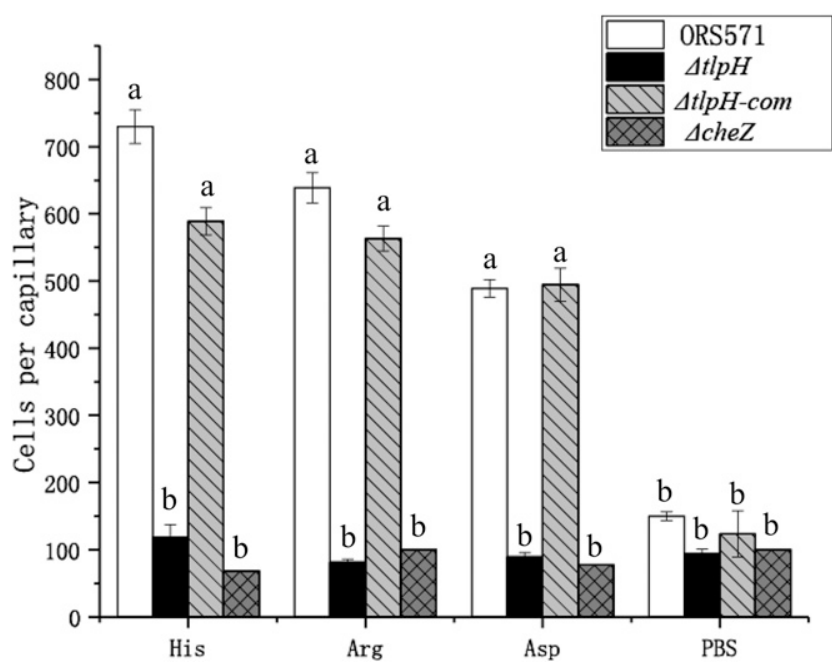

Fig. 6. Chemotaxis response of the $\Delta t l p H$ mutant and complemented strains to different amino acids. ORS571 and $\Delta c h e Z$ were used as positive and negative controls, respectively. Values are means \pm standard deviation calculated from at least three independent experiments. The same letters above the bars show no statistical difference according to the Duncan test $(P<0.05)$. 
wild type (W. Liu et al. 2017) but the chemotactic rings to succinate also increased significantly when an amino acid was added (Fig. 7A and B), indicating that TlpA1, similarly to $\mathrm{TlpH}$, was not involved in the succinate-chemotaxis-promoting effect of amino acids. In contrast, no ring was formed using the cheZ mutant strain, which was previously shown to be totally impaired in chemotaxis (X. Liu et al. 2018) and which was used as a negative control (Fig. 7A).

Generally, chemoeffectors regulate chemotaxis of bacteria through binding their cognate MCPs, affecting the autokinase activity of CheA (Parkinson et al. 2015). However, TlpH and TlpA1 are not involved in the increase of the chemotactic response to succinate, indicating that the interaction of ligands and cognate chemoreceptors was independent of the process. Therefore, it can be hypothesized that, in A. caulinodans ORS571, amino acids from seed exudates may have additional roles in chemotaxis. One possibility could be that these amino acids have an effect on the expression of other genes required for the chemotactic response such as those required for flagella synthesis and chemotactic pathway-related proteins, encoded by the che operon, previously characterized (W. Liu et al. 2018).
To verify this hypothesis, RT-qPCR was used to determine the changes of che and fla gene expression in response to amino acids. The expression levels of seven chemotaxis-pathwayrelated genes (cheY $:$ azc_0620, cheZ: azc_0621, cheA: azc_0661, cheW: azc_0662, cheY $2: a z c \_0663$, cheB: azc_0664, and cheR: azc_0665) and two flagella synthesis genes (azc_0647 and azc_0649) were analyzed in ORS571, strains $\triangle t l p A l$ and $\Delta t l p H$. An increase in the expression levels of these nine genes compared with a cognate negative control without amino acid treatment was observed in the three strains upon addition of amino acids (Fig. 8). Thus, we conclude that the flagella synthesis and chemotaxis-related genes are positively regulated by these amino acids.

In addition, the capillary assay was used to measure the effect of amino acids on the chemotactic response to succinate. In order to exclude the roles of chemotactic response to amino acids, there is no difference in amino acid concentration in capillaries (including succinate and cognate amino acid) and wells (including PBS buffer and cognate amino acid). Although amino acids influence succinate chemotaxis in the capillary assay, in contrast to the soft-agar plate assay, only arginine promotes the chemotactic response to succinate, and histidine

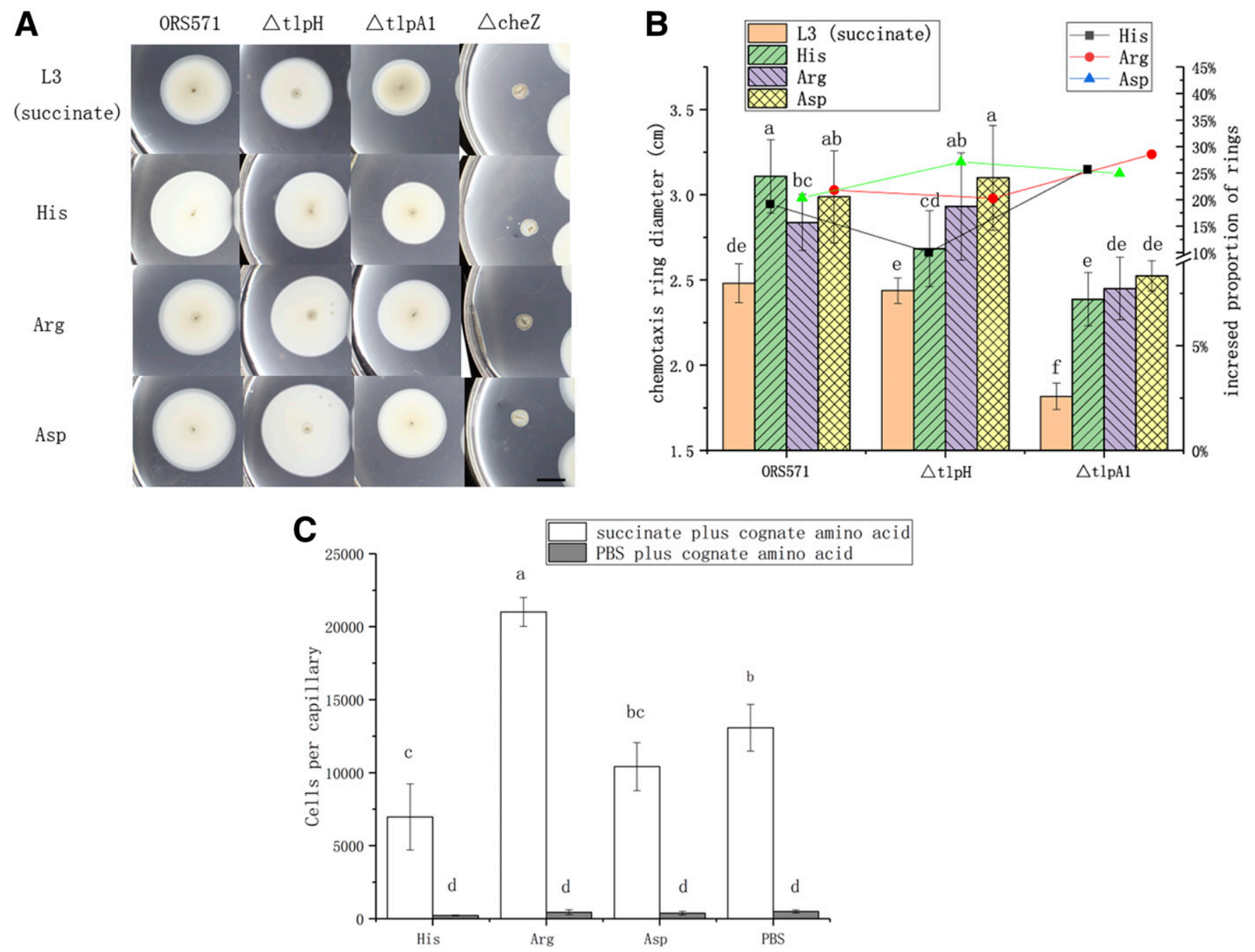

Fig. 7. Role of amino acids on the chemotactic response to succinate. Succinate was used as carbon source with $1 \mathrm{mM} \mathrm{NH} \mathrm{Cl}_{4}(\mathrm{~A}$ and $\mathrm{B})$. His $=$ histidine, $\mathrm{Arg}=$ arginine, and Asp = aspartate. A, Chemotactic rings of Azorhizobium caulinodans strains under different treatments. Scale bar represents $1 \mathrm{~cm}$. B, Diameter of each chemotactic ring (in centimeters) and ratio of the size of the chemotaxis rings after addition of amino acids as compared with succinate alone. $\mathbf{C}$, Cell number per capillary was counted at different conditions. PBS $=$ phosphate-buffered saline. There were no differences of amino acid concentration between cognate capillaries and wells. Values are means \pm standard deviation calculated from at least three independent experiments. The same letters above the bars show no statistical difference according to the Duncan test $(P<0.05)$. 


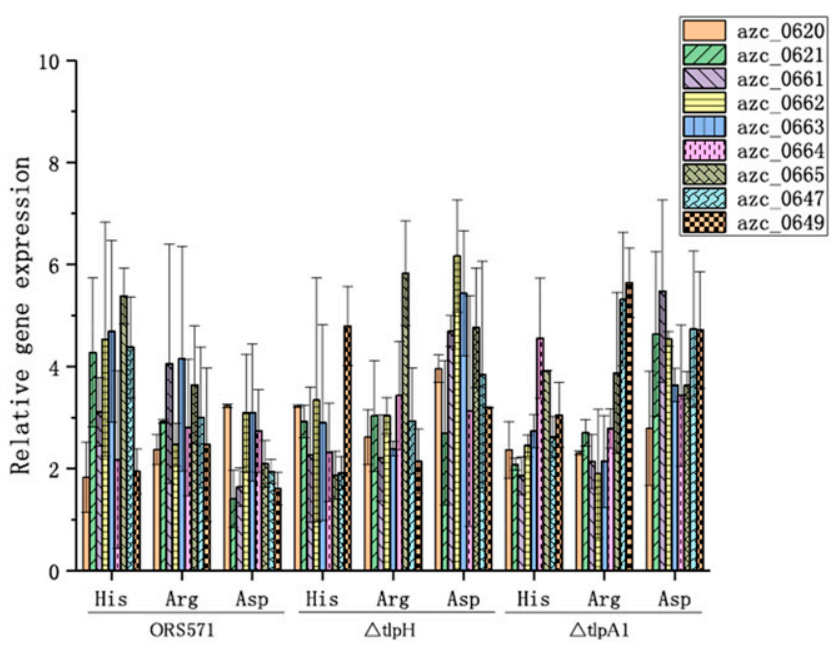

Fig. 8. Relative increase (ratio) in the expression level of che and fla genes in the wild type and $\triangle t l p H$ and $\triangle t l p A l$ mutants in the presence of amino acids compared with cognate strains in the absence of amino acids. His = histidine, $\operatorname{Arg}=$ arginine, and Asp $=$ aspartate. Values are means \pm standard deviation from at least three independent experiments. and aspartate reduce the chemotactic response to succinate (Fig. 7C). These results show that these amino acids have an indirect role on the chemotactic response to succinate, though the effect may be different in a capillary assay and soft-agar plate assay.

\section{The effect of amino acids}

in the biofilm formation and root colonization.

Root exudates can induce chemotactic response and biofilm formation, resulting in enhanced colonization of bacteria on root surfaces (Martins et al. 2018; Wall and Favelukes 1991; Yuan et al. 2015). To determine whether biofilm formation was induced by amino acids from $S$. rostrata seed exudates, we compared biofilm formation of ORS571 in the presence of amino acids on an abiotic surface. The three amino acids can decrease the formation of a biofilm by ORS571 and $\Delta t l p H$ at the same level (Fig. 9A), indicating that TlpH was not involved in the process. In the colonization assay, amino acids reduced the colonization of ORS571 and $\Delta t l p H$ on root surfaces separately (Fig. 9B). In a competitive colonization assay when the wild type and $\Delta t l p H$ were mixed in the proportions of $1: 1$, the final ratio on the root surface remained unchanged (Fig. 9C). This result differs from data obtained with $\operatorname{tlpA1}$ and icpB mutant strains (Jiang et al. 2016a; W. Liu et al. 2017), and
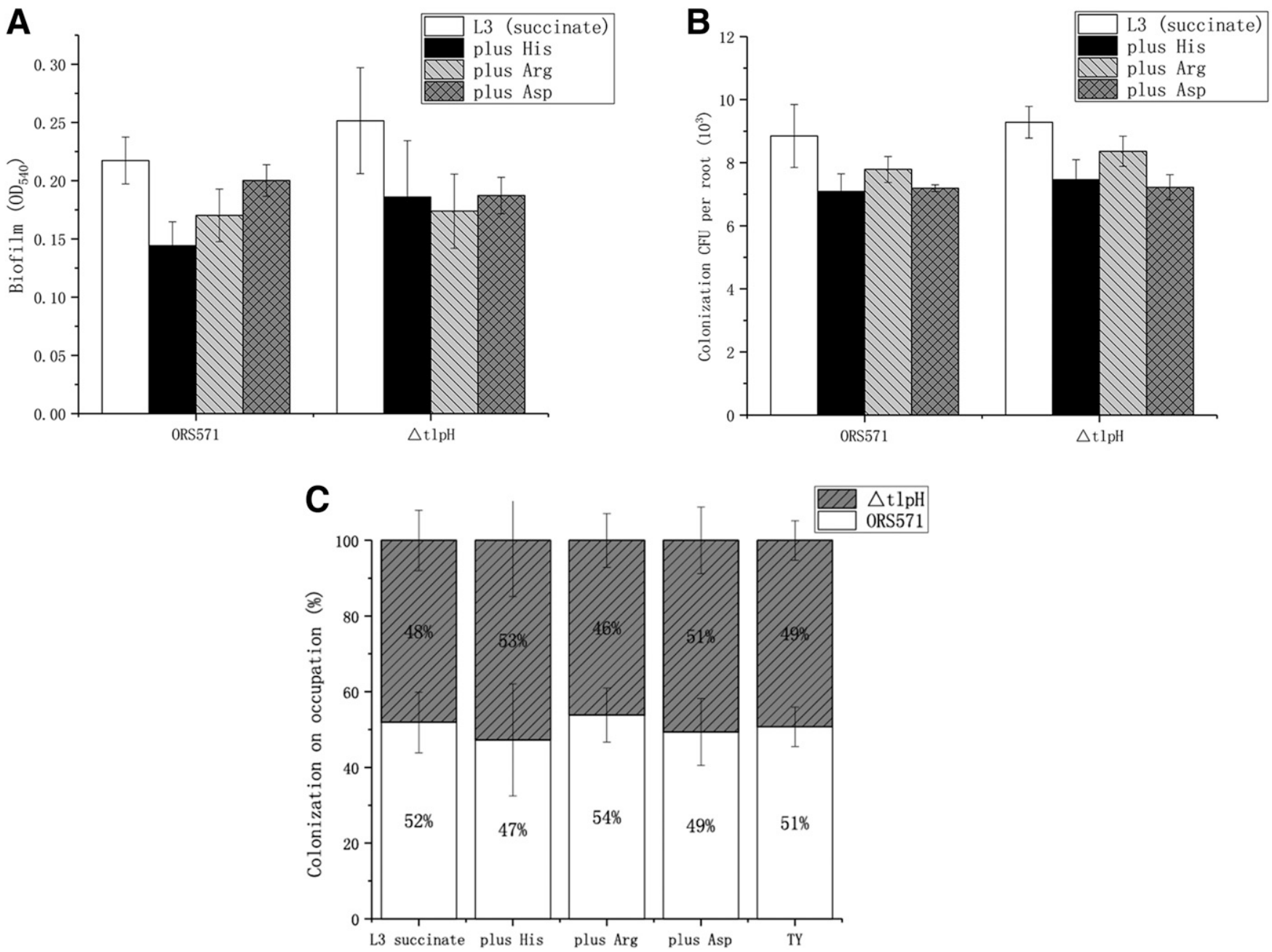

Fig. 9. Effect of amino acids on the biofilm formation and colonization of Azorhizobium caulinodans $\mathrm{ORS571}$. A, The optical density at $540 \mathrm{~nm}\left(\mathrm{OD}_{540}\right)$ value of each strain under different treatments was determined. His = histidine, Arg = arginine, and Asp = aspartate. B, Colonization of the wild type and $\Delta t l p H$ mutant strain with or without additional amino acids. $\mathbf{C}$, Competitive colonization of the wild type and $\Delta t l p H$ in different media. L3 succinate and tryptoneyeast extract medium were used as controls. 
suggests that $\mathrm{TlpH}$ is not involved in the root surface colonization properties of A. caulinodans ORS571.

TlpH is not involved in the root nodulation of $S$. rostrata.

Then, we assessed the role of $\mathrm{TlpH}$ in the root nodulation of $S$. rostrata. When $S$. rostrata seedlings were inoculated with ORS571 and $\Delta t l p H$ separately, there was no significant differences between the number or the appearance of the nodules (Fig. 10A). In a competitive nodulation assay, ORS571 and $\Delta t l p H$ were mixed in equal proportion, and we used two different inoculation methods under flooded and nonflooded conditions. (i) The $S$. rostrata seedlings were submerged with cells for 1 to $4 \mathrm{~h}$ before being transplanted to vermiculite. Goormachtig et al. (2004) had reported that, after being submerged for $1 \mathrm{~h}$ or $24 \mathrm{~h}$, the root hair invasion could be inhibited completely. (ii) The $S$. rostrata seedlings were transplanted to vermiculite and cultured for 1 day. Then, bacterial suspension was injected into vermiculite near the roots. This method was similar to the nonflooded conditions. No matter which method was used, root nodule numbers formed by ORS571 and $\Delta t l p H$ were similar in each plant (Fig. 10B). In addition, both ORS571 and $\Delta t l p H$ could form pink nodules and have sufficient leghemoglobin (data not shown). By assessing the shoot length of $S$. rostrata inoculated with ORS571 or $\Delta t l p H$ alone, we found no differences between them (Fig. 10C). Therefore, we concluded that $\mathrm{TlpH}$ did not affect the formation of root nodules of S. rostrata.

\section{DISCUSSION}

The composition and concentration of amino acids in seed exudates differ between species, creating a unique spermosphere (Webb et al. 2016, 2017). Histidine, arginine, and aspartate are the three most abundant amino acids produced in $S$. rostrata seed exudates, and they all can be used as chemotactic attractants toward $A$. caulinodans ORS571. A number of bacteria can use amino acids such as arginine, histidine, glutamate, glutamine, alanine, and other amino acids as a sole nitrogen source in the presence of a suitable carbon source. However, some other bacteria cannot utilize these amino acids. Dreyfus et al. (1988) had reported that most Azorhizobium strains, including A. caulinodans ORS571, cannot grow on histidine and arginine. In addition, Yao and Allen (2006) reported that Ralstonia solanacearum K60 cannot use isoleucine, leucine, lysine, and phenylalanine as carbon sources, though they are strong chemotactic effectors and common components in host exudates.

The A. caulinodans ORS571 genome contains genes involved in aspartate catabolism, and aspartate can be used as sole nitrogen source, although the growth rate was much slower
A

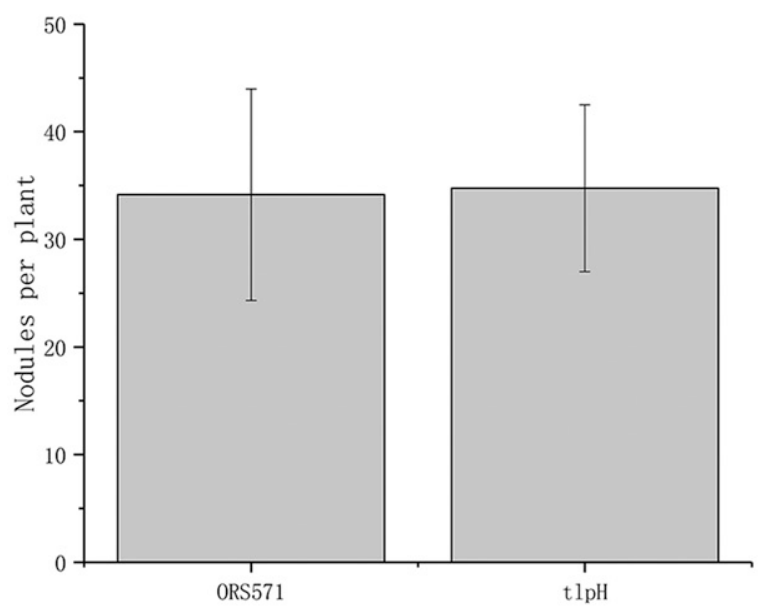

C

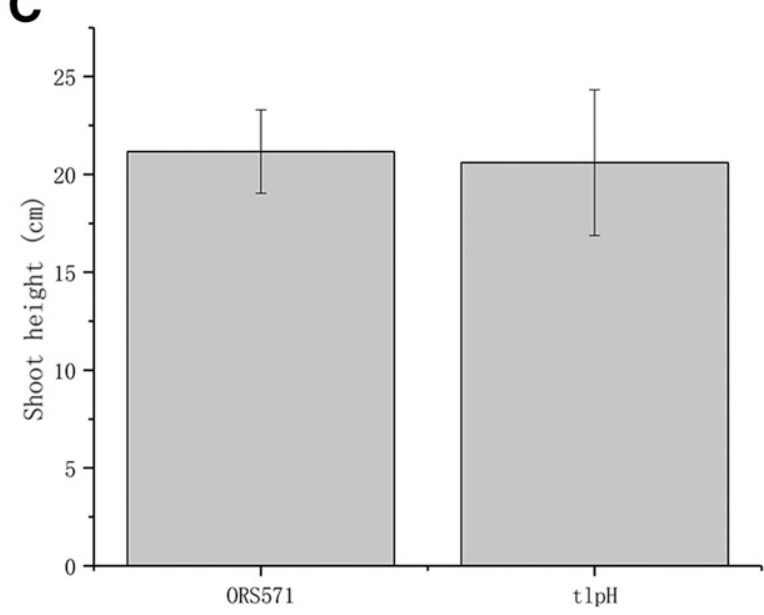

B

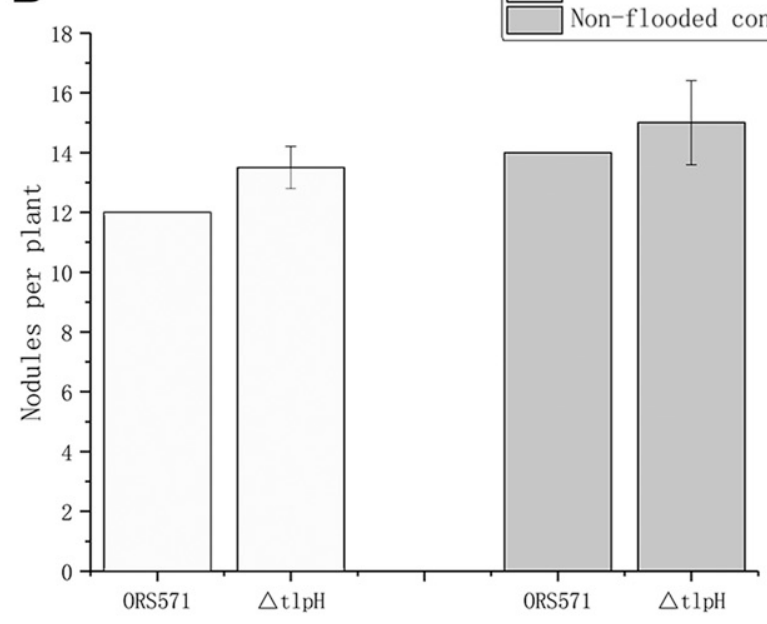


than with $\mathrm{NH}_{4} \mathrm{Cl}$ (Prival and Magasanik 1971). There are no genes encoding proteins involved with arginine and histidine catabolism in the A. caulinodans genome, excluding the possibility that the genes encoding the enzymes for the degradation pathway are subjected to catabolite repression in the presence of ammonia.

Among the 43 putative MCP proteins encoded by the A. caulinodans ORS571 genome, AZC_0254 and AZC_0821, both containing a dCache domain, were identified as possible amino acid receptors. The relative expression level of $a c z \_0821$ compared with that of $a z c_{-} 0254$ (Fig. 5) and the chemotaxis properties of a mutant strain (Fig. 6) led us to conclude that

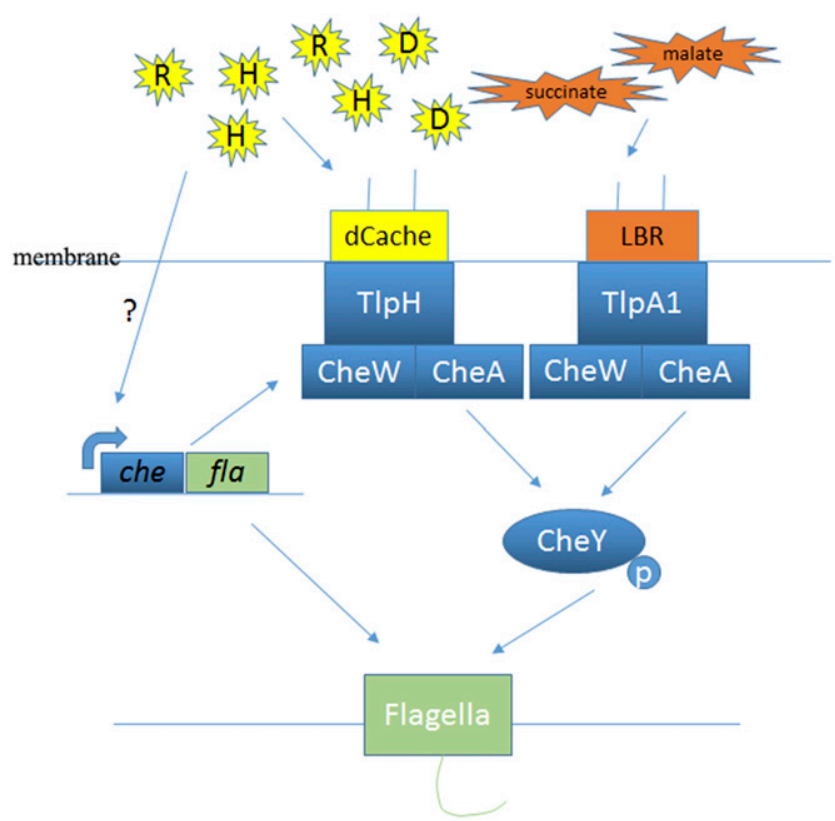

Fig. 11. Dual role of amino acids, working model. Direct role: amino acids (histidine, arginine, and aspartate) directly regulate chemotaxis of Azorhizobium caulinodans via interacting with $\mathrm{TlpH}$ containing the dCache domain. Succinate, malate, and some other attractants might bind to the ligand-binding region (LBR) of TlpA1. After binding ligands, both TlpH and TlpA1 can repress the autokinase activity of CheA, leading to a decrease in the concentration of CheY-P and, ultimately, in influencing the frequency of flagella rotation. Indirect role: amino acids also can modulate the expression levels of genes encoding chemotactic pathway (che) and flagella (fla) synthesis-related proteins through an unknown mechanism. Increase in the intracellular level of the Che and Fla proteins promoted by amino acids is correlated with an increase of the chemotactic response to succinate.
AZC_0821 was the chemoreceptor for the three amino acids. AZC_0821 was then renamed as TlpH, encoded by tlpH. Indeed, the LBRs of most amino-acid-sensing chemoreceptors have a dCache domain (Cache_1) (Matilla and Krell 2017; Upadhyay et al. 2016), and these chemoreceptors play important roles in microbe-host interactions. For example, both McpU from S. meliloti (Webb et al. 2014, 2017), which is important in chemotaxis toward host plant exudates, and VfcA from Vibrio fischeri (Brennan et al. 2013), involved in colonization of its mutualistic host, contain a dCache domain.

Analysis of the chemotactic behavior toward succinate led us to hypothesize that amino acids may have a "dual role": a direct role mediated through the cognate chemoreceptor $\mathrm{TlpH}$ and another role independent of TlpH. This was based on the observation that each of the three amino acids (histidine, arginine, and aspartate) led to an increase of the succinate-induced chemotactic ring formed by the wild type (Fig. 3D) and the $\triangle t l p A l$ and $\Delta t l p H$ mutant strains (Fig. 7A and B). Two hypotheses can be proposed. First, amino acids may increase the metabolism of succinate to form a sharp succinate gradient on soft-agar plate. However, in the presence of $1 \mathrm{mM} \mathrm{NH}_{4} \mathrm{Cl}$, the growth of $A$. caulinodans ORS571 and its derivative strains on succinate was not affected by the addition of amino acids. Although the presence of $\mathrm{NH}_{4} \mathrm{Cl}$ could prevent the utilization of aspartate, we could not absolutely exclude the possible effect of aspartate metabolism on enhancing the chemotactic ring of ORS571. Second, amino acids may be used as signals which can be sensed by other receptors, and then regulate the gene expression of chemotaxis-pathway-related and flagella synthesisrelated proteins. In other words, the indirect role of these amino acids may be achieved by regulation of gene expression but not ascribed to bacterial metabolism and growth.

The roles of histidine and aspartate on succinate chemotaxis were different in the capillary assay and the soft-agar plate assay. We also found that oxalate has different roles on the chemotactic response to succinate in the capillary assay and in the soft-agar plate assay (unpublished). Although these two assays both can be used to assess the chemotactic response to succinate, there are many differences between them. For example, the reaction time is different. The capillary assay can be finished within $1 \mathrm{~h}$, and the metabolism of substances can be ignored. In contrast, the soft-agar plate assay can be performed over $24 \mathrm{~h}, 48 \mathrm{~h}$, or even longer, when cells are able to grow and fix nitrogen, and some other cellular processes such as quorum sensing and secondary metabolism might be involved. The mechanisms and the differences between them need to be

Table 2. Bacteria strains and plasmids used in this study

\begin{tabular}{|c|c|c|}
\hline Strain or plasmid & Relevant characteristics ${ }^{\mathbf{a}}$ & Source or reference \\
\hline \multicolumn{3}{|l|}{ Strains } \\
\hline \multicolumn{3}{|l|}{ Escherichia coli } \\
\hline DH5 $\alpha$ & $\mathrm{F}^{-}$supE44 AlacU169 ( $\$ 80$ lacZAM15) hsdR17 recA1 endA1 gyrA96 thi-1 relA1 & Transgene \\
\hline \multicolumn{3}{|c|}{ 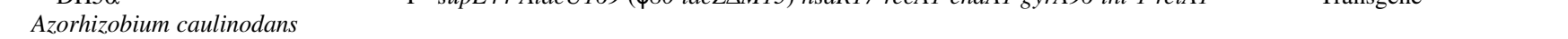 } \\
\hline ORS571 & Type strain; $\mathrm{Amp}^{\mathrm{R}}, \mathrm{Nal}^{\mathrm{R}}$ & Dreyfus et al. 1988 \\
\hline$\Delta c h e Z$ & ORS571 derivative; cheZ deletion mutant, $\mathrm{Amp}^{\mathrm{R}}, \mathrm{Nal}^{\mathrm{R}}, \mathrm{Gm}^{\mathrm{R}}$ & X. Liu et al. 2018 \\
\hline$\Delta t l p A 1$ & ORS571 derivative, tlpAl deletion mutant; $\mathrm{Amp}^{\mathrm{R}}, \mathrm{Nal}^{\mathrm{R}}, \mathrm{Gm}^{\mathrm{R}}$ & W. Liu et al. 2017 \\
\hline$\Delta t l p H$ & ORS571 derivative, tlpH deletion mutant; $\mathrm{Amp}^{\mathrm{R}}, \mathrm{Nal}^{\mathrm{R}}, \mathrm{Gm}^{\mathrm{R}}$ & This study \\
\hline$\triangle t l p H-C O M$ & ORS571 derivative, tlpH deletion mutant containing pBBR1MCS2-com & This study \\
\hline \multicolumn{3}{|c|}{ the } \\
\hline pCM351 & Allelic exchange vector, $\mathrm{Gm}^{\mathrm{R}}, \mathrm{Tc}^{\mathrm{R}}$ & Marx and Lidstrom 2002 \\
\hline pRK2013 & Helper plasmid, ColE1 replicon; Tra+ $\mathrm{Km}^{\mathrm{R}}$ & Ditta et al. 1980 \\
\hline pBBR1MCS-2 & Broad-host-range plasmid; $\mathrm{Km}^{\mathrm{R}}$ & Kovach et al. 1995 \\
\hline
\end{tabular}


studied further. The conditions in the soft-agar assay are likely to be more similar to the natural environment in soil.

When the cultures were treated with amino acids for $24 \mathrm{~h}$, the expression of che and fla genes in A. caulinodans strains was increased (Fig. 8). This finding may be correlated with the situation reported in Salmonella typhimurium, where arginine can modulate genes controlling the intracellular level of c-diGMP, involved in biofilm formation and motility (Mills et al. 2015). This in consistent with the second hypothesis described above as a possible mechanism. In the model depicted in Figure 11, amino acids not only can directly regulate chemotaxis via interaction with $\mathrm{TlpH}$ but also can play a role in the expression of the che and fla genes through an unknown mechanism. The chemotactic response to other attractants also needs chemotactic proteins and flagella encoded by che and fla, respectively. Thus, these amino acids play an indirect role on the chemotaxis behavior induced by other attractants such as succinate. Interestingly, unlike IcpB and TlpA1, TlpH does not influence the process of colonization and root nodulation, indicating that the direct chemotactic response to amino acids is not essential for the establishment of $A$. caulinodans and $S$. rostrata association. Generally, bacterial chemotaxis and biofilm formation both contribute to the initial contact with host roots (Caetano-Anolles et al. 1988; Timmusk et al. 2005). Although amino acids promote the chemotactic response of A. caulinodans, they decrease biofilm formation and root colonization (Fig. 9). These results show that the three amino acids may also participate in other cellular functions, especially biofilm formation, using mechanisms remaining to be elucidated. In summary, this work expands our understanding of how amino acids are involved in the interaction of bacteria and host plants, and might be beneficial to promote agricultural production in the future.

\section{MATERIALS AND METHODS}

Bacterial strains and construction.

A. caulinodans ORS571 (Dreyfus et al. 1988), its derivatives, and all plasmids used in this study are listed in Table 2.

\section{Media and growth conditions.}

A. caulinodans ORS571 and its derivative strains were grown in tryptone-yeast extract (TY) (Beringer 1974) medium. Standard L3 minimal medium (Jiang et al. 2016a; Nakajima et al. 2012) containing DL-sodium lactate at $10 \mathrm{mg} / \mathrm{ml}$ and $1 \mathrm{mM} \mathrm{NH}_{4} \mathrm{Cl}$ was used in biofilm formation. Modified L3 medium containing $10 \mathrm{mM}$ succinate instead of DL-sodium lactate at $10 \mathrm{mg} / \mathrm{ml}$ was used in growth and soft-agar chemotaxis experiments. E. coli was grown in Luria-Bertani medium.

\section{Preparation and analysis of seed exudates.}

Full-filled $S$. rostrata seed ( $40 \mathrm{~g}$ ) was selected, first soaked in concentrated sulfuric acid for $30 \mathrm{~min}$, then washed twice with sterile water, and finally added to $100 \mathrm{ml}$ of sterile water for 2 days at $37^{\circ} \mathrm{C}$. During soaking, the soaking solution was collected twice and, each time, $100 \mathrm{ml}$ of sterile water was added again. Finally, $300 \mathrm{ml}$ of soaking solution was collected, filtered, and stored at $-20^{\circ} \mathrm{C}$. The sample of seed exudates was analyzed on an amino acid analyzer (SYKAM S433D).

\section{Quantitative capillary chemotaxis assay.}

A quantitative capillary assay was performed as previously described (Reyes-Darias et al. 2016), with some modifications. A. caulinodans ORS571 and derivative strains were cultured overnight with TY medium. Then, cells were collected, washed three times, and resuspended to an $\mathrm{OD}_{600}$ of 0.01 with PBS. Next, $200 \mu \mathrm{l}$ each of diluted cells of wild-type and mutant strains were added separately into a 96-well plate. Capillaries were sealed at one end, and the open end was heated by flame, then inserted rapidly into PBS or solutions with amino acids. The height of liquid in a capillary was approximately $1 \mathrm{~cm}$. Then, capillaries with PBS or amino acids were inserted into each 96-well plate and incubated at $37^{\circ} \mathrm{C}$ for $1 \mathrm{~h}$. Finally, cells in a capillary were pipetted into $1 \mathrm{ml}$ of PBS, then counted by dilution-plate method. The experiment was replicated more than three times.

\section{Traditional and modified soft-agar plate assay.}

A traditional soft-agar plate assay was used to determine the roles of amino acids on succinate chemotaxis. The L3 soft plate

Table 3. PCR primers used in this study ${ }^{\mathrm{a}}$

\begin{tabular}{|c|c|c|c|}
\hline Primers & Sequences $\left(5^{\prime}-3^{\prime}\right)$ & Purpose & Reference \\
\hline tlpHUF-F KрnI & GGTACCTGCCGGTGATGCCCA & $\Delta t l p H$ mutant construct & This study \\
\hline tlpHUF-R NdeI & CATATGGCATAGAACTCCCTCGCCT & $\Delta t l p H$ mutant construct & This study \\
\hline tlpHDF-F AgeI & ACCGGTAGCCGGCTGCAATCGGAGAT & $\Delta t l p H$ mutant construct & This study \\
\hline tlpHDF-R SacI & 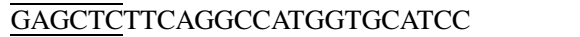 & $\Delta t l p H$ mutant construct & This study \\
\hline tlpH-com-F XhoI & CTCGAGAGCGGGGCTATCACGTGGTCGTCG & $\Delta t$ tpH complement construct & This study \\
\hline tlpH-com-R SalI & GTCGACTCAGGCGGCCGCCACCGAGCGCA & $\Delta t l p H$ complement construct & This study \\
\hline RT-0647-F & TCTGACAACATCGCGAACTC & RT-qPCR for $a z c \_0647$ & This study \\
\hline RT-0647-R & AGAAGCCATCACCATTGACC & RT-qPCR for $a z c \_0647$ & This study \\
\hline RT-0649-F & GCCAGCACCTACCAGAAGAC & RT-qPCR for $a z c \_0649$ & This study \\
\hline RT-0649-R & TTCAGGAACGTCTGCATCTG & RT-qPCR for $a z c \_0649$ & This study \\
\hline RT-0620-F & GGTTCTCGTCGTCGATGATT & RT-qPCR for $a z c \_0620$ & This study \\
\hline RT-0621-R & AAATCACGAGGCCGTACTTG & RT-qPCR for $a z c \_0620$ & This study \\
\hline RT-cheZ-F & AACCATCGACAATTCCATCG & RT-qPCR for $a z c \_0621$ & X. Liu et al. 2018 \\
\hline RT-cheZ-R & TGAAGACCATCAGCTTCACG & RT-qPCR for $a z c \_0621$ & X. Liu et al. 2018 \\
\hline RT-0661-F & TCATCAAGATCCCGCTTACC & RT-qPCR for $a z c \_0661$ & This study \\
\hline RT-0661-R & CTTGACCTGATGCTCGGAAT & RT-qPCR for $a z c \_0661$ & This study \\
\hline RT-0662-F & GTCTTCGTACCGGACCACAT & RT-qPCR for $a z c \_0662$ & This study \\
\hline RT-0662-R & ACCTCGTCGATCATCAGTCC & RT-qPCR for $a z c \_0662$ & This study \\
\hline RT-0663-F & CCTGCCTAGTGGTGGATGAT & RT-qPCR for $a z c \_0663$ & This study \\
\hline RT-0663-R & AACTCGATGCCTTCCATGAC & RT-qPCR for $a z c \_0663$ & This study \\
\hline RT-0664-F & ACATGGTGCTGGAGAAGTCC & RT-qPCR for $a z c \_0664$ & This study \\
\hline RT-0664-R & AACGACGCTTGTTTCTTCGT & RT-qPCR for $a z c \_0664$ & This study \\
\hline RT-0665-F & GAACGAGTCGCTGTTCTTCC & RT-qPCR for $a z c \_0665$ & This study \\
\hline RT-0665-R & CTGGACCTCGAACTGGTTGT & RT-qPCR for $a z c \_0665$ & This study \\
\hline RT-16S-F & ACGGATTTCTTCCAGCAATG & RT-qPCR for $16 S R N A$ & X. Liu et al. 2018 \\
\hline RT-16S-R & ACCGGCAGTCCCTTTAGAGT & RT-qPCR for $16 S R N A$ & X. Liu et al. 2018 \\
\hline
\end{tabular}

\footnotetext{
${ }^{a}$ Engineered restriction sites are underlined. RT-qPCR $=$ real-time quantitative PCR.
} 
with $0.3 \%$ agar was supplemented with $10 \mathrm{mM}$ succinate and with an additional $10 \mathrm{mM}$ histidine, $1 \mathrm{mM}$ arginine, or $1 \mathrm{mM}$ aspartate. The L3 soft plate with $10 \mathrm{mM}$ succinate was used as a control. A modified soft-agar plate was used to define chemotactic characteristics of amino acids. First, the petri dish was tilted on the table, and the soft-agar medium with $10 \mathrm{mM}$ succinate and $10 \mathrm{mM}$ histidine or other amino acids was added on a Petri dish. After the underlying medium has solidified, Petri dishes were placed horizontally, and soft-agar medium with $10 \mathrm{mM}$ succinate only was added on the top. When the upper medium was solidified, $5 \mu$ l of cells with a density of $\mathrm{OD}_{600}=0.6$ was dropped on the center of plate. After incubation at $37^{\circ} \mathrm{C}$ for $48 \mathrm{~h}$, the chemotactic rings were photographed.

\section{Bioinformatics analysis.}

Amino acid sequences of MCP in A. caulinodans were selected from the NCBI database or Mist3 database (Ulrich and Zhulin 2010). PSI-BLAST was carried out with the amino sequence of each MCP to query target proteins. The amino acid sequences of target proteins were used to build a multiple sequence alignment via T-coffee (Notredame et al. 2000). Pfam (Finn et al. 2016) and SMART (Letunic and Bork 2018) were used to analyze the domain of selected proteins. Pairwise sequence alignment was achieved using the Needleman-Wunsch algorithm.

\section{Construction of $\Delta t l p H$ mutant and complemented strains.}

To construct the $t l p H$ gene mutant, a 724-bp upstream fragment (UF) and 708-bp downstream fragment (DF) of gene tlpH were amplified by PCR using two pairs of primers (tlpHUFF/tlpHUF-R and tlpHDF-F/tlpHDF-R) (Table 3). The amplicons of each fragment and allelic exchange vector, pCM351 (Marx and Lidstrom 2002), were digested with cognate restriction enzymes (for UF and pCM351, KpnI and NdeI; for DF and pCM351::UF, AgeI and SacI); then, the digested products were linked by T4 DNA ligase. The resulting product, pCM351:: UF::down, was introduced into A. caulinodans ORS571 through conjugation for allelic exchange with the helper pRK2013 (Ditta et al. 1980). Correct homologous recombinants were selected by antibiotics and verified by PCR with the primer pair tlpHUFF/tlpHDR-R (Table 3).

For complementation, the fragment including the $t l p H$ intact open reading frame and 702-bp upstream sequence was amplified and cloned into the XhoI and SalI sites of the broad-hostrange cloning vector pBBR1MCS-2 (Kovach et al. 1995). The constructing plasmid pBBR1MCS2-com was transformed into E. coli $\mathrm{DH} 5 \alpha$. Then, pBBR1MCS2-com was introduced into $\Delta t l p H$ through triparental mating, as previously described. One correct resulting mutant strain was named $\Delta t l p H$-com and used in subsequent experiments.

\section{RT-qPCR.}

A. caulinodans ORS571 cells cultured in different growth phases, mediums, and additions of amino acids were used to isolate total RNA through a TransZol Up Plus RNA kit (Transgen Biotech). The RNA quality and concentration were confirmed by a Nanodrop 2000. cDNA (1,000 ng) was generated with the TransScript One-Step gDNA removal kit, then diluted $10^{1}$-fold and $10^{5}$-fold to be used as temple in subsequent qPCR. The comparative cycle threshold method (Schmittgen and Livak 2008) was used to analyze the results. PCR primers used for amplification of $c h e$ and fla genes, as well as 16S RNA primers used for standardization, are listed in Table 3.

\section{Biofilm formation assay.}

The cristal violet (CV) method (Black et al. 2015) was used to measure biofilm formation qualitatively and quantitatively.
Cells $(15 \mu \mathrm{l})$ with an $\mathrm{OD}_{600}$ of 2.5 were added into 96-well plates, and each well was filled with $150 \mu \mathrm{l}$ of L3 medium with or without amino acids. After incubating at $37^{\circ} \mathrm{C}$ for 3 days, cultures were washed with sterile water five times. Next, $1.0 \% \mathrm{CV}$ was added into each well and incubated for $20 \mathrm{~min}$ at room temperature. Then, each well was washed with sterile water five times and dried in the air. Finally, $200 \mu \mathrm{l}$ of $30 \%$ acetic acid was added into each well and the liquid in each well was transferred to new 96-well plates to determine the $\mathrm{OD}_{540}$ with a microplate reader (Tecan Infinite M200).

\section{Colonization of $S$. rostrata seedlings.}

Seed of $S$. rostrata were immersed in concentrated sulfuric acid for $30 \mathrm{~min}$ to sterilize their surface and induce uniform germination. Then, concentrated sulfuric acid was removed, and the seed, rinsed by sterilized water at least five times, were germinated in the dark for $48 \mathrm{~h}$ at $37^{\circ} \mathrm{C}$. Cells grown overnight in TY medium were collected and washed by sterilized water, then resuspended in different L3 medium (succinate instead of sodium lactate) with or without amino acids. Each suspension was adjusted to an $\mathrm{OD}_{600}$ of 0.6. Germinated seedlings were soaked into each suspension for $4 \mathrm{~h}$. Then, the surface of seedlings was washed by sterilized water five times. After vortexing, bacteria were reisolated from seedling roots and counted via serial dilutions on solid TY plates. In the competitive colonization assay, the wildtype strain and $\Delta t l p H$ were mixed at a ratio of $1: 1$. Other treatments were similar to the above method. When wildtype strains and $\Delta t l p H$ were isolated from seedling roots and cultured on solid TY plates, the colonies on the plates were simultaneously transferred to TY agar plates with or without gentamicin to identify the ratio between the wild-type strain and $\Delta t l p H$.

\section{Root nodulation assay of $S$. rostrata.}

A. caulinodans strains cultured overnight were adjusted to an $\mathrm{OD}_{600}$ of 0.6. For root inoculation before being transplanted, $S$. rostrata seedlings grown as depicted in colonization of $S$. rostrata seedlings were inoculated with bacterial suspension for $4 \mathrm{~h}$. Next, $S$. rostrata seedlings were transplanted into vermiculite and cultured for 45 days. Then, nodule numbers and shoot length were counted. For root inoculation after being transplanted, seedlings at similar lengths were selected and transplanted into vermiculite. After culturing for 1 day, the bacterial suspension was injected into vermiculite near the roots with a sterile pipette. The nodule formation was analyzed after culturing for 45 days.

\section{Statistical analysis.}

Differences among the treatments were statistically analyzed using the analysis of variance, Duncan's multiple range test $(P<0.05)$, and the least significant difference test $(P<0.05)$ using the Statistical Package for the Social Sciences (version 20.0; SPSS Inc.).

\section{ACKNOWLEDGMENTS}

We thank R. Shen for mutant strain construction and C. Elmerich for helpful and insightful comments on the manuscript.

\section{AUTHOR-RECOMMENDED INTERNET RESOURCES}

\section{PSI-BLAST:}

https://mistdb.com/genomes/GCF_000010525.1/signal-genes? componentId $=6325 \&$ ranks $=$ chemotaxis, $\mathrm{mcp}$

Needleman-Wunsch algorithm: https://www.ebi.ac.uk/Tools/emboss 


\section{LITERATURE CITED}

Allard-Massicotte, R., Tessier, L., Lécuyer, F., Lakshmanan, V., Lucier, J. F., Garneau, D., Caudwell, L., Vlamakis, H., Bais, H. P., and Beauregard, P. B. 2016. Bacillus subtilis early colonization of Arabidopsis thaliana roots involves multiple chemotaxis receptors. MBio 7:e01664-16.

Beringer, J. E. 1974. R factor transfer in Rhizobium leguminosarum. J. Gen. Microbiol. 84:188-198.

Bible, A. N., Khalsa-Moyers, G. K., Mukherjee, T., Green, C. S., Mishra, P., Purcell, A., Aksenova, A., Hurst, G. B., and Alexandre, G. 2015. Metabolic adaptations of Azospirillum brasilense to oxygen stress by cell-to-cell clumping and flocculation. Appl. Environ. Microbiol. 81: 8346-8357.

Black, W. P., Wang, L., Davis, M. Y., and Yang, Z. 2015. The orphan response regulator EpsW is a substrate of the DifE kinase and it regulates exopolysaccharide in Myxococcus xanthus. Sci. Rep. 5: Article 17831.

Brencic, A., and Winans, S. C. 2005. Detection of and response to signals involved in host-microbe interactions by plant-associated bacteria. Microbiol. Mol. Biol. Rev. 69:155-194.

Brennan, C. A., DeLoney-Marino, C. R., and Mandel, M. J. 2013. Chemoreceptor VfcA mediates amino acid chemotaxis in Vibrio fischeri. Appl. Environ. Microbiol. 79:1889-1896.

Caetano-Anollés, G., Wall, L. G., De Micheli, A. T., Macchi, E. M., Bauer, W. D., and Favelukes, G. 1988. Role of Motility and Chemotaxis in Efficiency of Nodulation by Rhizobium meliloti. Plant Physiol. 86: 1228-1235.

Cai, T., Cai, W., Zhang, J., Zheng, H., Tsou, A. M., Xiao, L., Zhong, Z., and Zhu, J. 2009. Host legume-exuded antimetabolites optimize the symbiotic rhizosphere. Mol. Microbiol. 73:507-517.

Capoen, W., Oldroyd, G., Goormachtig, S., and Holsters, M. 2010. Sesbania rostrata: A case study of natural variation in legume nodulation. New Phytol. 186:340-345.

Corral-Lugo, A., De la Torre, J., Matilla, M. A., Fernández, M., Morel, B., Espinosa-Urgel, M., and Krell, T. 2016. Assessment of the contribution of chemoreceptor-based signalling to biofilm formation. Environ. Microbiol. 18:3355-3372.

Coskun, D., Britto, D. T., Shi, W., and Kronzucker, H. J. 2017. How plant root exudates shape the nitrogen cycle. Trends Plant Sci. 22: 661-673.

Ditta, G., Stanfield, S., Corbin, D., and Helinski, D. R. 1980. Broad host range DNA cloning system for gram-negative bacteria: Construction of a gene bank of Rhizobium meliloti. Proc. Natl. Acad. Sci. U.S.A. 77: 7347-7351.

Dreyfus, B., Garcia, J.-L., and Gillis, M. 1988. Characterization of Azorhizobium caulinodans gen. nov., sp. nov., a stem-nodulating nitrogen-fixing bacterium isolated from Sesbania rostrata. Int. J. Syst. Evol. Microbiol. 38:89-98.

Dreyfus, B. L., Elmerich, C., and Dommergues, Y. R. 1983. Free-living Rhizobium strain able to grow on $\mathrm{n}(2)$ as the sole nitrogen source. Appl. Environ. Microbiol. 45:711-713.

Elmerich, C., Dreyfus, B., and Aubert, J. P. 1983. Nicotinic-acid requirement and degradation by Sesbania-Rhizobium strain ORS571. FEMS Microbiol. Lett. 19:281-284.

Elmerich, C., Dreyfus, B. L., Reysset, G., and Aubert, J. P. 1982. Genetic analysis of nitrogen fixation in a tropical fast-growing Rhizobium. EMBO J. 1:499-503.

Finn, R. D., Coggill, P., Eberhardt, R. Y., Eddy, S. R., Mistry, J., Mitchell, A. L., Potter, S. C., Punta, M., Qureshi, M., Sangrador-Vegas, A., Salazar, G. A., Tate, J., and Bateman, A. 2016. The Pfam protein families database: Towards a more sustainable future. Nucleic Acids Res. 44: D279-D285.

Goormachtig, S., Capoen, W., James, E. K., and Holsters, M. 2004. Switch from intracellular to intercellular invasion during water stress-tolerant legume nodulation. Proc. Natl. Acad. Sci. U.S.A. 101:6303-6308.

Greer-Phillips, S. E., Stephens, B. B., and Alexandre, G. 2004. An energy taxis transducer promotes root colonization by Azospirillum brasilense. J. Bacteriol. 186:6595-6604.

Hartmann, A., Schmid, M., van Tuinen, D., and Berg, G. 2009. Plant-driven selection of microbes. Plant Soil 321:235-257.

Jiang, N., Liu, W., Li, Y., Wu, H., Zhang, Z., Alexandre, G., Elmerich, C., and Xie, Z. 2016a. A chemotaxis receptor modulates nodulation during the Azorhizobium caulinodans-Sesbania rostrata symbiosis. Appl. Environ. Microbiol. 82:3174-3184.

Jiang, N., Liu, W., Li, Y., and Xie, Z. 2016b. Comparative genomic and protein sequence analyses of the chemotaxis system of Azorhizobium caulinodans. Wei Sheng Wu Xue Bao 56:1256-1265.
Kalinin, Y., Neumann, S., Sourjik, V., and Wu, M. 2010. Responses of Escherichia coli bacteria to two opposing chemoattractant gradients depend on the chemoreceptor ratio. J. Bacteriol. 192:1796-1800.

Kamilova, F., Kravchenko, L. V., Shaposhnikov, A. I., Azarova, T., Makarova, N., and Lugtenberg, B. 2006. Organic acids, sugars, and Ltryptophane in exudates of vegetables growing on stonewool and their effects on activities of rhizosphere bacteria. Mol. Plant-Microbe Interact. 19:250-256.

Kovach, M. E., Elzer, P. H., Hill, D. S., Robertson, G. T., Farris, M. A., Roop, R. M., 2nd, and Peterson, K. M. 1995. Four new derivatives of the broad-host-range cloning vector pBBR1MCS, carrying different antibiotic-resistance cassettes. Gene 166:175-176.

Krell, T. 2018. Exploring the (almost) unknown: Archaeal two-component systems. J. Bacteriol. 200:e00774-17.

Kuroda, A., Kumano, T., Taguchi, K., Nikata, T., Kato, J., and Ohtake, H. 1995. Molecular cloning and characterization of a chemotactic transducer gene in Pseudomonas aeruginosa. J. Bacteriol. 177:7019-7025.

Lacal, J., García-Fontana, C., Muñoz-Martínez, F., Ramos, J. L., and Krell, T. 2010. Sensing of environmental signals: Classification of chemoreceptors according to the size of their ligand binding regions. Environ. Microbiol. 12:2873-2884.

Letunic, I., and Bork, P. 2018. 20 years of the SMART protein domain annotation resource. Nucleic Acids Res. 46:D493-D496.

Liu, W., Sun, Y., Shen, R., Dang, X., Liu, X., Sui, F., Li, Y., Zhang, Z., Alexandre, G., Elmerich, C., and Xie, Z. 2018. A chemotaxis-like pathway of Azorhizobium caulinodans controls flagella-driven motility, which regulates biofilm formation, exopolysaccharide biosynthesis, and competitive nodulation. Mol. Plant-Microbe Interact. 31: 737-749.

Liu, W., Yang, J., Sun, Y., Liu, X., Li, Y., Zhang, Z., and Xie, Z. 2017. Azorhizobium caulinodans transmembrane chemoreceptor TlpA1 Involved in host colonization and nodulation on roots and stems. Front. Microbiol. 8:1327.

Liu, X., Liu, W., Sun, Y., Xia, C., Elmerich, C., and Xie, Z. 2018. A cheZlike gene in Azorhizobium caulinodans is a key gene in the control of chemotaxis and colonization of the host plant. Appl. Environ. Microbiol. 84:e01827-17.

Liu, Y., Chen, L., Wu, G., Feng, H., Zhang, G., Shen, Q., and Zhang, R. 2017. Identification of root-secreted compounds involved in the communication between cucumber, the beneficial Bacillus amyloliquefaciens, and the soil-borne pathogen Fusarium oxysporum. Mol. PlantMicrobe Interact. 30:53-62.

López-Baena, F. J., Ruiz-Sainz, J. E., Rodríguez-Carvajal, M. A., and Vinardell, J. M. 2016. Bacterial molecular signals in the Sinorhizobium fredii-Soybean symbiosis. Int. J. Mol. Sci. 17:755.

López-Farfán, D., Reyes-Darias, J. A., and Krell, T. 2017. The expression of many chemoreceptor genes depends on the cognate chemoeffector as well as on the growth medium and phase. Curr. Genet. 63:457-470.

Martins, S. J., Medeiros, F. H. V., Lakshmanan, V., and Bais, H. P. 2018. Impact of seed exudates on growth and biofilm formation of Bacillus amyloliquefaciens ALB629 in Common Bean. Front. Microbiol. 8: 2631.

Marx, C. J., and Lidstrom, M. E. 2002. Broad-host-range cre-lox system for antibiotic marker recycling in gram-negative bacteria. Biotechniques 33 : 1062-1067.

Matilla, M. A., and Krell, T. 2017. Chemoreceptor-based signal sensing. Curr. Opin. Biotechnol. 45:8-14

Mills, E., Petersen, E., Kulasekara, B. R., and Miller, S. I. 2015. A direct screen for c-di-GMP modulators reveals a Salmonella typhimurium periplasmic L-arginine-sensing pathway. Sci. Signal. 8:ra57.

Nakajima, A., Aono, T., Tsukada, S., Siarot, L., Ogawa, T., and Oyaizu, H. 2012. Lon protease of Azorhizobium caulinodans ORS571 is required for suppression of $r e b$ gene expression. Appl. Environ. Microbiol. 78: 6251-6261.

Notredame, C., Higgins, D. G., and Heringa, J. 2000. T-Coffee: A novel method for fast and accurate multiple sequence alignment. J. Mol. Biol. 302:205-217.

Parkinson, J. S., Hazelbauer, G. L., and Falke, J. J. 2015. Signaling and sensory adaptation in Escherichia coli chemoreceptors: 2015 update. Trends Microbiol. 23:257-266.

Prival, M. J., and Magasanik, B. 1971. Resistance to catabolite repression of histidase and proline oxidase during nitrogen-limited growth of Klebsiella aerogenes. J. Biol. Chem. 246:6288-6296.

Qiu, L., Li, Q., Zhang, J., Chen, Y., Lin, X., Sun, C., Wang, W., Liu, H., and Zhang, B. 2017. Migration of endophytic diazotroph Azorhizobium caulinodans ORS571 inside wheat (Triticum aestivum L) and its effect on microRNAs. Funct. Integr. Genomics 17:311-319. 
Reyes-Darias, J. A., García, V., Rico-Jiménez, M., Corral-Lugo, A., and Krell, T. 2016. Identification and characterization of bacterial chemoreceptors using quantitative capillary and gradient plate chemotaxis assays. Bio-Protoc. 6:e1789.

Reyes-Darias, J. A., García, V., Rico-Jiménez, M., Corral-Lugo, A., Lesouhaitier, O., Juárez-Hernández, D., Yang, Y., Bi, S., Feuilloley, M., Muñoz-Rojas, J., Sourjik, V., and Krell, T. 2015. Specific gammaaminobutyrate chemotaxis in pseudomonads with different lifestyle. Mol. Microbiol. 97:488-501.

Rico-Jiménez, M., Muñoz-Martínez, F., García-Fontana, C., Fernandez, M., Morel, B., Ortega, A., Ramos, J. L., and Krell, T. 2013a. Paralogous chemoreceptors mediate chemotaxis towards protein amino acids and the non-protein amino acid gamma-aminobutyrate (GABA). Mol. Microbiol. 88:1230-1243.

Rico-Jiménez, M., Muñoz-Martínez, F., Krell, T., Gavira, J. A., and PinedaMolina, E. 2013b. Purification, crystallization and preliminary crystallographic analysis of the ligand-binding regions of the PctA and PctB chemoreceptors from Pseudomonas aeruginosa in complex with amino acids. Acta Crystallogr. Sect. F Struct. Biol. Cryst. Commun. 69:1431-1435.

Salah Ud-Din, A. I. M., and Roujeinikova, A. 2017. Methyl-accepting chemotaxis proteins: A core sensing element in prokaryotes and archaea. Cell. Mol. Life Sci. 74:3293-3303.

Schmittgen, T. D., and Livak, K. J. 2008. Analyzing real-time PCR data by the comparative C(T) method. Nat. Protoc. 3:1101-1108.

Taguchi, K., Fukutomi, H., Kuroda, A., Kato, J., and Ohtake, H. 1997. Genetic identification of chemotactic transducers for amino acids in Pseudomonas aeruginosa. Microbiology 143:3223-3229.

Timmusk, S., Grantcharova, N., and Wagner, E. G. 2005. Paenibacillus polymyxa invades plant roots and forms biofilms. Appl. Environ. Microbiol. 71:7292-7300.

Ulrich, L. E., and Zhulin, I. B. 2010. The MiST2 database: A comprehensive genomics resource on microbial signal transduction. Nucleic Acids Res. 38:D401-D407.

Upadhyay, A. A., Fleetwood, A. D., Adebali, O., Finn, R. D., and Zhulin, I. B. 2016. Cache domains that are homologous to, but different from PAS domains comprise the largest superfamily of extracellular sensors in prokaryotes. PLOS Comput. Biol. 12:e1004862.

Wadhams, G. H., and Armitage, J. P. 2004. Making sense of it all: Bacterial chemotaxis. Nat. Rev. Mol. Cell Biol. 5:1024-1037.
Wall, L. G., and Favelukes, G. 1991. Early recognition in the Rhizobium meliloti-alfalfa symbiosis: Root exudate factor stimulates root adsorption of homologous rhizobia. J. Bacteriol. 173:3492-3499.

Webb, B. A., Compton, K. K., Del Campo, J. S. M., Taylor, D., Sobrado, P., and Scharf, B. E. 2017. Sinorhizobium meliloti chemotaxis to multiple amino acids is mediated by the chemoreceptor McpU. Mol. PlantMicrobe Interact. 30:770-777.

Webb, B. A., Helm, R. F., and Scharf, B. E. 2016. Contribution of individual chemoreceptors to Sinorhizobium meliloti chemotaxis towards amino acids of host and nonhost seed exudates. Mol. Plant-Microbe Interact. 29:231-239.

Webb, B. A., Hildreth, S., Helm, R. F., and Scharf, B. E. 2014 Sinorhizobium meliloti chemoreceptor McpU mediates chemotaxis toward host plant exudates through direct proline sensing. Appl. Environ. Microbiol. 80:3404-3415.

Webster, G., Jain, V., Davey, M. R., Gough, C., Vasse, J., Dénarié, J., and Cocking, E. C. 1998. The flavonoid naringenin stimulates the intercellular colonization of wheat roots by Azorhizobium caulinodans. Plant Cell Environ. 21:373-383.

Wuichet, K., Alexander, R. P., and Zhulin, I. B. 2007. Comparative genomic and protein sequence analyses of a complex system controlling bacterial chemotaxis. Methods Enzymol. 422:1-31.

Wuichet, K., and Zhulin, I. B. 2010. Origins and diversification of a complex signal transduction system in prokaryotes. Sci. Signal. 3: ra50.

Yang, Y., Pollard, A. M., Höfler, C., Poschet, G., Wirtz, M., Hell, R., and Sourjik, V. 2015. Relation between chemotaxis and consumption of amino acids in bacteria. Mol. Microbiol. 96:1272-1282.

Yao, J., and Allen, C. 2006. Chemotaxis is required for virulence and competitive fitness of the bacterial wilt pathogen Ralstonia solanacearum. J. Bacteriol. 188:3697-3708.

Yuan, J., Zhang, N., Huang, Q., Raza, W., Li, R., Vivanco, J. M., and Shen, Q. 2015. Organic acids from root exudates of banana help root colonization of PGPR strain Bacillus amyloliquefaciens NJN-6. Sci. Rep. 5: Article 13438.

Zhalnina, K., Louie, K. B., Hao, Z., Mansoori, N., da Rocha, U. N., Shi, S., Cho, H., Karaoz, U., Loqué, D., Bowen, B. P., Firestone, M. K., Northen, T. R., and Brodie, E. L. 2018. Dynamic root exudate chemistry and microbial substrate preferences drive patterns in rhizosphere microbial community assembly. Nat. Microbiol. 3:470-480. 